\title{
A Study on Selection Strategies for Battery Electric Vehicles Based on Sentiments, Analysis, and the MCDM Model
}

\author{
Xiaosong Ren $\mathbb{D}^{1},{ }^{1}$ Sha Sun $\mathbb{D}^{1},{ }^{1}$ and Rong Yuan $\mathbb{D D}^{2}$ \\ ${ }^{1}$ School of Management Science and Engineering, Shanxi University of Finance and Economics, Taiyuan 030031, China \\ ${ }^{2}$ College of Management and Economics, Chongqing University, Chongqing 400044, China \\ Correspondence should be addressed to Xiaosong Ren; renxs@sxufe.edu.cn
}

Received 11 March 2021; Revised 3 August 2021; Accepted 9 August 2021; Published 18 August 2021

Academic Editor: Maria Angela Butturi

Copyright ( $\odot 2021$ Xiaosong Ren et al. This is an open access article distributed under the Creative Commons Attribution License, which permits unrestricted use, distribution, and reproduction in any medium, provided the original work is properly cited.

Under the goal of carbon peak and carbon neutrality, developing battery electric vehicles (BEVs) is an important way to reduce carbon emissions in the transportation sector. To popularize BEVs as soon as possible, it is necessary to study selection strategies for BEVs from the perspective of consumers. Therefore, the Latent Dirichlet Allocation (LDA) model based on fine-grained sentiment analysis is combined with the multi-criteria decision-making (MCDM) model to assess ten types of BEV alternatives. Fine-grained sentiment analysis is applied to find the vehicle attributes that consumers care about the most based on the word-ofmouth data. The LDA model is suggested to divide topics and construct the indicator system. The MCDM model is used to rank vehicles and put forward the corresponding optimization path to increase consumer purchases of BEVs in China. The results show that (a) via the LDA model based on fine-grained sentiment analysis, attributes that consumers care most about are divided into five topics: dynamics, technology, safety, comfort, and cost; (b) based on the DEMATEL technique, the dimensions in the order of importance are as follows: safety, technology, dynamics, comfort, and cost; (c) the price is the most important criteria that affect customers' satisfaction by the DANP model; and (d) based on the VIKOR model, the selection strategies present that Aion S is highlighted as the best choice, and the optimization path is discussed to promote the performance of BEVs to increase customers' satisfaction. The findings can provide a reference for improving the sustainable development of the automobile industry in China. The proposed framework serves as the basis for further discussion of BEVs.

\section{Introduction}

With the rapid growth of the number of vehicles, the issue of energy consumption and greenhouse gas (GHG) emissions in the transportation sector are attracting increasing attention worldwide [1, 2]. According to the International Energy Agency, the transportation sector accounts for about $24.6 \%$ of the world's energy-related carbon dioxide emissions [3]. Automobile emissions have been a major source of emissions in the transportation sector [4-6], which aggravates the deterioration of the ecological environment and causes a series of health problems [7-9]. China owns the largest automobile market in the world since 2009 [10], and car ownership has exceeded 200 million by 2020, indicating that the issue of energy security and environmental pollution will become more prominent $[11,12]$. To alleviate these problems, governments and automobile manufacturers pay more attention to develop cleaner and more efficient alternative-fuel vehicles $[12,13]$, which induces the upsurge of battery electric vehicles (BEVs) [14-17]. And, BEVs will become the mainstream of vehicle sales by 2035 in China [18].

However, in the early stage of the development of BEVs, only relying on market forces is not enough for the commercialization and popularization of BEVs [19]. Thus, the Chinese government has formulated a series of incentive policies for consumers and BEV manufacturers [20-23], e.g., purchase subsidies, tax exemption, free parking, and driving privileges $[24,25]$. Based on the above incentives, from 2011 to 2019 , the production and sales volume of BEVs increased from 5655 and 5579 to 1,020,000, and 972,000, respectively. More importantly, as a result of the reduction of subsidies, 
sales of BEVs in July 2019 dropped significantly compared with June 2019, with a drop of 59.9\% [26]. This means that the advantages of policy support offered by BEVs are not enough to persuade consumers [27]. Previous studies have highlighted that the low market share of BEVs is related to consumers' perceived uncertainty $[28,29]$, which means that exploring the selection strategies of consumers will help enlarge the market share of BEVs [30, 31].

Existing studies on vehicle selection and comparison are mainly based on life cycle assessment (LCA) [32], statistical methods [33], and multicriteria decision-making method $(\mathrm{MCDM})[34,35]$, but the influence of consumer sentiments on vehicle selection strategies is ignored. Therefore, this study attempts to use the Latent Dirichlet Allocation (LDA) model based on the fine-grained sentiment analysis, that is, to analyze the sentiment polarity of online reviews, to reveal the customer's sentiment towards the attributes of BEVs' models, and to extract the attributes that consumers care most about as evaluation criteria. The topic analysis is applied to distinguish dimensions. This method considers the index from the consumer's point of view and effectively avoids the problem of artificial selection. Based on this, quantitative cause-effect relationships among vehicle attributes are included as an important point in BEVs' assessment. It makes up for the lack of considering the correlation between attributes in the existing research. Taking ten domestic BEVs models in China as research samples, a detailed and practical optimization path is put forward, which solves the shortage that the existing research only considers evaluation and selection.

The main tasks of this study include the following aspects: (1) Using consumers' word-of-mouth data from Autohome website and LDA model based on the finegrained sentiment analysis, a new evaluation index system of BEVs selection based on customer perspective is constructed. (2) Decision Making Trial and Evaluation Laboratory (DEMATEL) technique is utilized in this study to identify the interaction between criteria within each dimension. Analytic network process (ANP) is then employed to determine the weights of criteria and dimensions. (3) Modified Vlse Kriterijuska Optimizacija I Komoromisno Resenje (VIKOR) is applied to calculate the indicator gaps and comprehensive evaluation scores for ten types of BEVs in China. Based on the above research framework, the customer selection strategies and the manufacturer optimization paths are proposed. The specific analysis process is shown in Figure 1.

The remainder of this study is organized as follows. Section 2 gives a literature review. Section 3 describes the methods. Section 4 presents the results. Section 5 conducts a discussion. Section 6 presents the conclusions.

\section{Literature Review}

This section briefly reviews the literature from three aspects: application of machine-learning methods in the field of electric vehicles (EVs), application of MCDM models in vehicle selection, and the factors influencing consumers' choice of BEVs.
2.1. Application of Machine-Learning Methods in the Field of $E V s$. With the rise of big data analysis and machine learning, many scholars have applied it in the field of EVs. Bas et al. [36] applied supervised machine-learning techniques to identify key elements influencing EVs' adoption and classify potential EVs purchasers. De Clercq et al. [37] made use of two machine-learning techniques, i.e., LDA model and multi-label classification algorithm to extract subject words from patent texts and classify patents into multiple cooperative patent categories. Yang et al. [38] evaluated and optimized relevant policies of China's new energy vehicle industry based on text mining technology. In the study of Naumanen et al. [39], LDA model was used to identify emerging research topics according to papers and patents related to heavy duty BEVs. Aguilar-Dominguez et al. [40] used a machine-learning method to evaluate the availability of five vehicles participating in the vehicle-to-home services. Basso et al. [41] applied the probabilistic Bayesian machine-learning model to solve the route selection problem and found the best route for EVs by predicting the energy consumption within the limited driving distance. Ma et al. [42] adopted big data and textmining technologies to analyze online behavior of Chinese consumers and to identify the factors affecting consumers' preferences. Different from previous research on online comment mining, emotion analysis is not only the mining and analysis of consumers' online comments but also the extraction and interpretation of emotions expressed in texts [43]. The purpose of sentiment analysis is to investigate the emotion polarity of online texts and divide them as positive, neutral, and negative [44]. However, only a few papers in the literature apply sentiment analysis to the analysis of consumers' recognition of vehicle. Via big data platform, Deep Learning techniques were employed by Jena [44] to explore and classify consumers' sentiment towards EVs in India.

2.2. Application of MCDM Models in Vehicle Selection. According to previous studies on MCDM, MCDM models could be classified into the following two categories. The first category is applied to calculate the weights of alternatives, such as the Simultaneous Evaluation of Criteria and Alternatives (SECA) [34], Analytical Hierarchy Process (AHP) [35], ANP [45], and Stepwise Weight Assessment Ratio Analysis (SWARA) [46]. In the second category, the ranking of alternatives is based on comprehensive scores such as Measurement of Alternatives and Ranking according to Compromise Solution (MARCOS) [34], Complex Proportional Assessment (COPRAS) [46], VIKOR [47], Technique for Order of Preference by Similarity to Ideal Solution (TOPSIS) [48], ELimination and Choice Expressing the REality (ELECTRE) [49], Preference Ranking Organization Method for Enrichment Evaluation (PROMETHEE) [50], and so on. In addition, the combination of these methods has also attracted the attention of academic circles. To enhance the robustness, scholars have combined the single method and formed the newly developed hybrid MCDM models. 


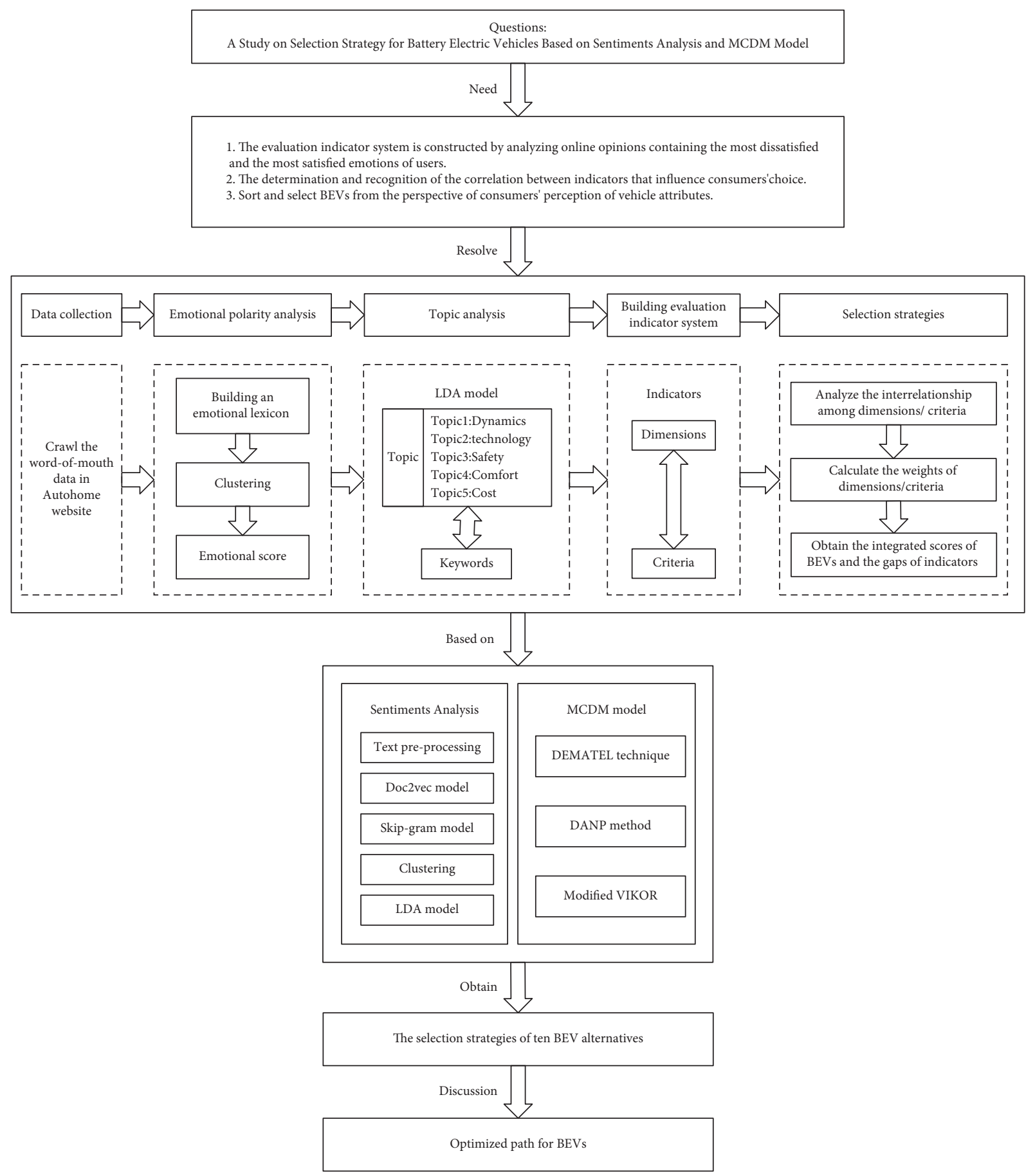

Figure 1: Analysis procedure of the study.

In recent years, based on the hybrid MCDM models, a series of scientific and systematic theoretical explorations have emerged, especially in vehicle evaluation and selection. For example, Li et al. [47] adopted an MCDM combining AHP and VIKOR to rank and optimize four types of vehicles, including EVs, gas vehicles, methanol vehicles, and ethanol vehicles, to provide references for decision-makers in the new energy automotive industry. Using intuitionistic fuzzy set and TOPSIS methods, Onat et al. [48] evaluated and ranked the performance scores of alternative vehicles, which indicated that hybrid electric vehicles were the most proper choice. Das et al. [51] developed a fuzzy AHPEVAMIX hybrid model for evaluating and comparing the performance of electric vehicles in Asia. Tzeng et al. [52] developed a hybrid approach including AHP, TOPSIS, and VIKOR for alternative fuel buses like fuel cell, electricity, and methanol. The final ranking shows that the hybrid electric bus is the most suitable choice. Liang et al. [53] presented a 
fuzzy MCDM assessment model to evaluate and compare alternative-fuel vehicles, and the research results show that biodiesel vehicles are the best choice.

2.3. The Factors Influencing Consumers' Choice of BEVs. Vehicle purchasing is closely related to consumers' acceptance. Up to now, many studies have explored the possible drivers or barriers that influence consumers' choice of BEVs [54]. Liu et al. [55] found that the customer experience is the main decisive factor in buying BEVs. Kim et al. [56] concluded that customers with good driving experiences and knowledge are more likely to buy BEVs in Korea. Li et al. [57] found in their study that family factors, such as scale, income, and location, can influence consumers' choice of BEVs. She et al. [58] demonstrated that older, experienced, and environmentally conscious consumers were more interested in buying a BEV in Tianjin. Besides, safety, reliability, and range were the three key obstacles to BEV sales. Dong et al. [59] recognized that urban consumers' purchasing decisions would be changed by psychological factors such as subjective norms, feelings and emotions, personal norms, and perceived behavioural control. Li et al. [60] argued that fast charging time and battery warranty can promote consumers' adoption of BEVs. Das et al. [51] evaluated the performance of EVs based on nine attributes, such as the price, battery capacity, torque, charging time, overall weight, seating capacity, driving range, top speed, and acceleration. Nazari et al. [31] stressed that the elimination of concerns such as technical uncertainty, limited vehicle styling, and charging time will increase the utilization rate of BEVs. In addition to price and battery technology, Ma et al. [42] suggests that the design of the exterior and interior has a strong appeal to consumers. Kukova et al. [61] pointed out that internal space, operating reliability, and braking are also important attributes affecting whether consumers choose BEVs or not. Li et al. [24] believed that the implementation of financial incentives, such as purchase subsidies and tax exemption, played an indispensable role in promoting Chinese consumers to adopt BEVs. In the study of Cheng et al. [4], reduction in battery charging time and maintenance cost were the first two major measures to motivate consumers to purchase BEVs. Although existing studies have considered the influence of demographic, technological, and psychological factors on consumer purchasing behavior, researchers have shown that consumers' decision to purchase BEVs is largely determined by the vehicle's performance characteristics $[62,63]$. Therefore, in this study, only the influence of vehicle attributes on BEVs selection is considered, and other factors are not considered.

To sum up, although previous studies on vehicle selection have made some progress, there are still the following limitations: (1) Some studies have not clearly explained how to select indicators. In addition, some studies have pointed out that indicators are obtained through literature review, but this process is susceptible to subjective factors. (2) The indicators are interdependent, but many studies have not clearly identified the cause-effect relationship. (3) The literature does not provide beneficial guidance for consumers to choose BEVs in China. There is no mention of the optimization paths of specific models. Therefore, this study adopts the LDA model based on fine-grained sentiment analysis to obtain indicators. The MCDM model is used to identify interrelationships, and to propose selection strategies and optimization paths for BEVs in China from the point of view of consumers.

\section{Methodology}

This research proposes a hybrid model combining finegrained sentiment analysis and MCDM model to form a novel framework to study consumers' selection strategies for BEVs. Specifically, the LDA model based on fine-grained sentiment analysis is applied to identify dimensions and criteria based on the word-of-mouth data of BEVs in Autohome website. DEMATEL technique is used to construct an influential network relationship map (INRM). DEMATEL-based Analytic Network Process (DANP) is used to confirm the impact weight of each evaluation indicator based on ANP [64]. Finally, VIKOR is not only used to evaluate and obtain the selection strategies but also to find the gaps in each evaluation indicator and make optimal paths to improve consumers' adoption.

\subsection{Sentiment Analysis}

3.1.1. Text Preprocessing. In this study, the Scrapy framework developed in Python is used to crawl the word-ofmouth data. However, invalid data in the crawled text will affect the effectiveness of data output. If these invalid data are introduced into subsequent models, it can have a significant impact on the results of the analysis. Therefore, text preprocessing should be carried out after obtaining the word-of-mouth data of the Autohome website. In this paper, the process of text preprocessing is divided into several steps, including data splitting, data cleaning, text segmentation by jieba clauses, removing stop words, adding self-defined automobile dictionary, and data transformation.

3.1.2. Doc2vec Model. After preprocessing the data, the text data are divided into a test set and a training set based on a certain ratio. Then, we build a Doc2vec model based on the training set data, train the test set data with the Doc2vec model, and finally build a support vector machine classifier to calculate the accuracy of the test set.

3.1.3. Skip-Gram Model. Emotional granularity can be divided into two types, i.e., positive and negative emotional polarity; however, to increase the accuracy of the regression model, the emotional granularity is further refined, i.e., emotional polarity is divided into five types (very satisfied, satisfied, fair, dissatisfied, and very dissatisfied). The text preprocessed data are trained 100 times using word2vec to obtain a Skip-gram model (a method for learning highdimensional word representations that capture rich semantic relationships between words) with a word vector dimension of 200 dimensions. The results of the text 
preprocessing are used to obtain the emotion words with high word frequency, and then the Skip-gram model is used to obtain words that are similar to the emotion words to obtain a more comprehensive emotion vocabulary.

3.1.4. Clustering. The clustering algorithm divides the emotional lexicon of word-of-mouth into five categories based on the difference between the customers' expectations and the actual perception of the BEVs.

3.1.5. LDA Model. Topic models are algorithms for discovering key topics in a large and unstructured collection of text [65]. LDA is one of the topic models, which is applied to automatically discover topics in the text that consumers are most satisfied and least satisfied with. The core computational problem for topic models is to use the collected text to infer the hidden topic structure [66]. Thus, this study identifies the consumer concerns by using the LDA model, to discover key topics from the collected text.

\subsection{MCDM Model}

3.2.1. DEMATEL Technique. DEMATEL technique is a systematic factor analysis method to detect the cause-effect relationships between complicated indicators using graph theory and matrix tools [67], originally proposed by the Battelle Research Centre in 1972 [68]. DEMATEL has been used to solve complicated real-world problems by building an INRM [69], such as optimal online travel agencies [70], regional innovation capacity [71], and sustainable online consumption [72]. Thus, the steps of this technique are summarized as follows.

Step 1. Finding the average direct effect matrix.

The mutual direct effect among criteria is evaluated by the knowledge-based experts. The scales ranged from 0 to 4 where " 0 " means "absolutely no effect" and " 4 " means "very high effect." " 1 ," “ 2 ," and " 3 " mean "low effect," "middle effect," and "high effect," respectively. By a pairwise comparison, we can obtain these groups of direct matrices by scores, where $i j$ represents the influence from criterion $i$ to criterion $j$. After that, we can calculate an average direct effect matrix $G$ (as seen in equation (1)), where each criterion is the average of the corresponding criteria in the experts' direct matrices [73].

$$
G=\left[\begin{array}{ccccc}
g_{c}^{11} & \ldots & g_{c}^{1 j} & \ldots & g_{c}^{1 n} \\
\vdots & & \vdots & & \vdots \\
g_{c}^{i 1} & \ldots & g_{c}^{i j} & \ldots & g_{D}^{i n} \\
\vdots & & \vdots & & \vdots \\
g_{c}^{n 1} & \ldots & g_{c}^{n j} & \ldots & g_{c}^{n n}
\end{array}\right],
$$

Step 1. Setting up the normalized direct-influence matrix $X$. (3)

The matrix $X$ can be acquired by using equations (2) and

$$
X=S \times G, \quad S>0,
$$

where

$$
S=\min i, j\left\{\frac{1}{\max _{i} \sum_{j=1}^{n} g_{c}^{i j}}, \frac{1}{\max _{j} \sum_{i=1}^{n} g_{c}^{i j}}\right\}, \quad i, j \in\{1,2, \ldots, n\} .
$$

Step 1. Computing the total influence matrix $T c$.

The total influence matrix $T_{c}$ can be derived from equation (4), where matrix $I$ denotes a unit matrix.

$$
\begin{aligned}
T_{c} & =X+X^{2}+X^{3}+\cdots+X^{\theta} \\
& =X\left(I+X+X^{2}+\cdots+X^{\theta-1}\right)(I-X)(I-X)^{-1} \\
& =X\left(I-X^{\theta}\right)(I-X)^{-1}=X(I-X)^{-1},
\end{aligned}
$$

where $\quad X=\left[x_{c}^{i j}\right]_{n \times n}, 0 \leq\left[x_{c}^{i j}\right] \leq 1,0<\sum_{j=1}^{n} x_{c}^{i j} \leq 1$, and $0<\sum_{i=1}^{n} x_{c}^{i j} \leq 1$, and at least the sum of one row or column (but not all) equals one; $\lim _{\theta \longrightarrow \infty} X^{\theta}=[0]_{n \times n}$.

Step 4. Building the INRM and analyzing the results.

The sum of rows and the sum of columns of total influence matrix $T_{c}$ can be, respectively, represented by vector $r$ and vector $s$ according to equations (5)-(6), where $r_{i}$ indicates the total influence of criterion $i$ on others, the $s_{i}$ denotes the total influences received by criterion $j$ from other criteria. When $i=j$ and $i, j \in\{1,2, \ldots, n\}$, the vector $\left(r_{i}+s_{i}\right)$ expresses the importance of criterion $i$ in the question. Likewise, the vector $\left(r_{i}-s_{i}\right)$ identifies the degree of causality among indicators. Simultaneously, if $\left(r_{i}-s_{i}\right)$ is positive, the criterion $i$ influences other criteria. On the contrary, if $\left(r_{i}-s_{i}\right)$ is negative, the criterion $i$ is affected by others. Finally, draw the INRM in which the vertical axis represents $\left(r_{i}+s_{i}\right)$ and the horizontal axis represents $\left(r_{i}-s_{i}\right)$ [74].

$$
\begin{aligned}
T_{c} & =\left[t_{c}^{i j}\right]_{n \times n}, \quad i, j \in\{1,2, \ldots, n\}, \\
r & =\left[\sum_{j=1}^{n} t_{c}^{i j}\right]_{n \times 1}=\left[t_{c}^{i}\right]_{n \times 1}=\left(r_{1}, \ldots, r_{i}, \ldots, r_{n}\right)^{\prime}, \\
s & =\left[\sum_{i=1}^{n} t_{c}^{i j}\right]_{1 \times n}=\left[t_{c}^{i}\right]_{1 \times n}=\left(s_{1}, \ldots, s_{i}, \ldots, s_{n}\right)^{\prime} .
\end{aligned}
$$

The total influence matrices has two forms, one is $T_{c}=\left[t_{i j}\right.$ $c]_{n \times n}$ (equation (7)), where $n$ represents the number of the

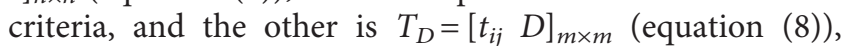
where $m$ represents the number of dimensions.

$$
\begin{aligned}
& \begin{array}{ccccc}
D_{1} & \cdots & D_{j} & \cdots & D_{m} \\
c_{11} \cdots c_{1 n_{1}} & c_{j 1} \cdots c_{j n_{j}} & c_{m 1} \cdots c_{m n_{m}}
\end{array} \\
& D_{1} \quad \vdots\left[\begin{array}{llllll}
T_{c}^{11} & \ldots & T_{c}^{1 j} & \ldots & T_{c}^{1 n}
\end{array}\right]
\end{aligned}
$$

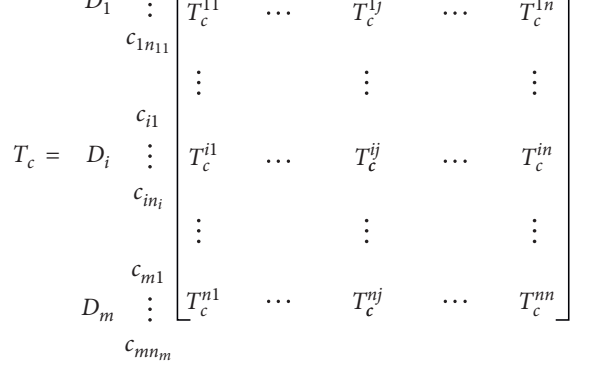


3.2.2. DANP Method. The ANP method was first proposed by Saaty [64], to deal with the interdependence and feedback problems among indicators $[75,76]$. It originates from the AHP but eliminates the deficiency of AHP, which assumes that the indicators are independent of each other [77]. However, the weighted super-matrix in the ANP method lacks rationality because it assumes that each cluster has the same weight [78]. Therefore, the DANP is an appropriate method to obtain the influential weights by improving the normalization process and addressing the interrelationships among indicators [45]. It has been used in many different fields, such as low-carbon energy planning [79], material selection [80], and renewable energy selection [81]. Thus, the process of this technique involves the following steps.

Step 1. Calculating the normalized total-influential matrix $T_{\text {nor }} D$.

According to equations (8) and (9), matrix $T_{\text {nor }} D$ is framed through normalizing the total-influential matrix $T_{D}$. First, the sum of each row in matrix $T_{D}$ can be expressed as $t_{D}^{i}=\sum_{j=1}^{m} t_{D}^{i j}$, where $m$ represents the number of dimensions. Then, the normalized total-influential matrix $T_{\text {nor }} D$ is calculated by dividing the elements in each row by the sum of the row, so that $T_{\text {nor }} D=\left[t_{i j} D /{ }_{t i} D\right]_{m \times m}$. Meanwhile, the sum of each row in matrix $T_{\text {nor }} D$ equals one, so that $\sum_{j=1}^{m} t_{D}^{n o r i j}=1$.

$$
\begin{aligned}
T_{D} & =\left[\begin{array}{ccc}
t_{D}^{11} & t_{D}^{1 j} & t_{D}^{1 m} \\
t_{D}^{i 1} & t_{D}^{i j} & t_{D}^{i m} \\
t_{D}^{m 1} & t_{D}^{m j} & t_{D}^{m m}
\end{array}\right] \longrightarrow \sum_{j=1}^{m} t_{D}^{i j}=t_{D}^{i}, \\
T_{D}^{\text {nor }} & =\left[\begin{array}{ccccc}
t_{D}^{11} & \ldots & \frac{t_{D}^{1 j}}{t_{D}^{1}} & \ldots & \frac{t_{D}^{1 m}}{t_{D}^{1}} \\
t_{D}^{1} & & & \\
\vdots & & \vdots & \\
\frac{t_{D}^{i 1}}{t_{D}^{i}} & \ldots & \frac{t_{D}^{i j}}{t_{D}^{i}} & \ldots & \frac{t_{D}^{i m}}{t_{D}^{i}} \\
\vdots & & \vdots & \vdots \\
\frac{t_{D}^{m 1}}{t_{D}^{m}} & \ldots & \frac{t_{D}^{m j}}{t_{D}^{m}} & \ldots & \frac{t_{D}^{m m}}{t_{D}^{m}}
\end{array}\right] .
\end{aligned}
$$

Step 2. Exporting the normalized matrix $T_{\text {nor }} c$ by dimensions and clusters.
A new matrix $T_{\text {nor }} c$ is acquired by normalizing $T_{c}$ with the total degrees of effect and influence of the dimensions and clusters:

$$
\begin{aligned}
& \begin{array}{ccccc}
D_{1} & \cdots & D_{j} & \cdots & D_{m} \\
c_{11} \cdots c_{1 n_{1}} & c_{j 1} \cdots c_{j n_{j}} & & c_{m 1} \cdots c_{m n_{m}}
\end{array} \\
& c_{11} \\
& \left.\left.\begin{array}{lc}
D_{1} & \vdots \\
c_{1 n_{11}}
\end{array}\right] \begin{array}{ccccc}
T_{c}^{\text {nor }_{11}} & \ldots & T_{c}^{\text {nor }_{1 j}} & \ldots & T_{c}^{\text {nor }_{1 n}}
\end{array}\right]
\end{aligned}
$$

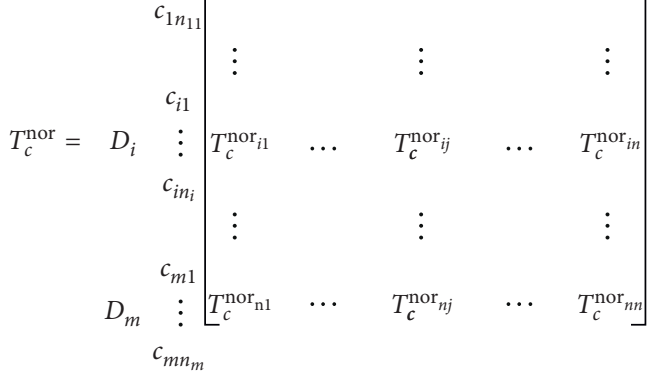

Step 3. Determining the unweighted super-matrix $W_{c}$.

The unweighted super-matrix $W_{c}$ is obtained by transposing the normalized matrix $T_{\text {nor }} c$ :

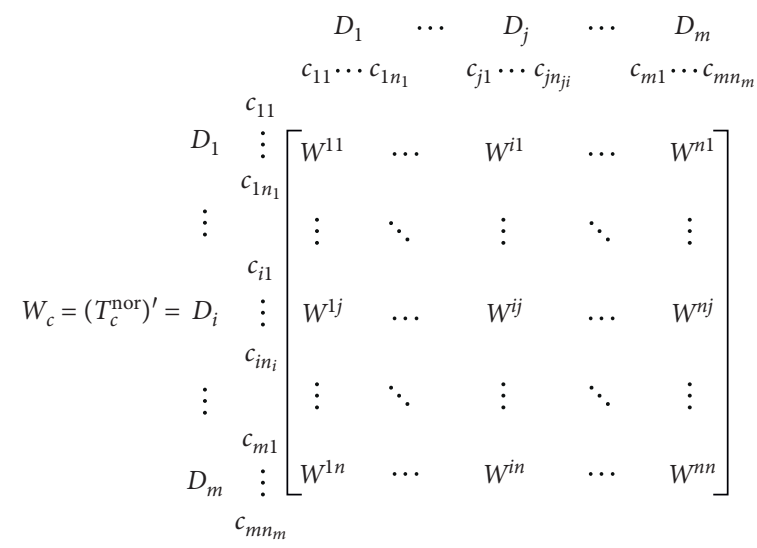

Step 4. Constructing the weighted super-matrix $W * c$.

The normalized total-influential matrix $T_{\text {nor }} D$ is obtained by equation (9) and the unweighted super-matrix $W_{c}$ is obtained by equation (11). Thus, using equation (12), a weighted super-matrix $W * c$, which improves the traditional ANP by using equal weights to make it appropriate for the real world, can be obtained by the product of $T_{\text {nor }} c$ and $W_{c}$, i.e., $W * c=T_{\text {nor }} D * W_{c}$. This demonstrates that the influential level values are the basis of normalization to determine a weighted super-matrix.

$$
W_{c}^{*}=T_{D}^{\text {nor }} W_{c}\left[\begin{array}{cccccc}
t_{D}^{\text {nor }_{11}} \times W_{c}^{11} & \ldots & t_{D}^{\text {nor }{ }^{11}} \times W_{c}^{i 1} & \ldots & t_{D}^{\text {nor }_{m 1}} \times W_{c}^{m 1} \\
\vdots & & & & & \vdots \\
t_{D}^{\text {nor }_{1 j}} \times W_{c}^{1 j} & \ldots & t_{D}^{\text {nor }_{i j}} \times W_{c}^{i j} & & t_{D}^{\text {nor }_{m j}} \times W_{c}^{m j} \\
\vdots & & \vdots & & \vdots \\
t_{D}^{\text {nor }_{1 m}} \times W_{c}^{1 m} & \ldots & t_{D}^{\text {nor }_{i m}} \times W_{c}^{i m} & \ldots & t_{D}^{\text {nor }_{m m}} \times W_{c}^{m m}
\end{array}\right] .
$$


Step 5. Calculating the influential weights of the criteria.

The influential weights $w=\left(w_{1}, \ldots, w_{j}, \ldots, w_{n}\right)$ can be obtained according to the weighted super-matrix $W * c$, and multiplied several times until it converges a stable supermatrix, so that $\lim _{\alpha \longrightarrow \infty}(W * c)^{\alpha}$, where $\alpha$ is a positive integer number.

3.2.3. VIKOR Method. The VIKOR method was first proposed by Opricovic to optimize the multiple criteria of complicated systems in 1998 [82]. It is applied to rank and select from a set of alternatives given the conflicting criteria. VIKOR is also the compromise ranking method, based on the concept of the Positive-ideal (or the aspired level) solution and Negative-ideal (or the worst level) solution [83]. So, the order of results can be compared by "proximity" to the "ideal" alternative $[82,84,85]$. In this study, the modified VIKOR method can be used to increase customers' satisfaction in alternatives that are influenced by the interaction of various factors. All of the steps for VIKOR are presented as follows:

Step 1. Determining the positive-ideal solution, negativeideal solution, and the gap.

According to the concepts of VIKOR, $f * j$ is the positiveideal point of assessment criteria, which indicates the best value (aspiration level); In contrast, $f-j$ is a negative-ideal point, which means the worst value. In this study, the best value is set as $f * j=10$ [64]. Likewise, the worst value is set as $f-j=0$ with scores of criteria ranging from 0 (dissatisfied) to 10 (satisfied). This is different from the traditional VIKOR, in which the positive-ideal solution is set as the maximum of all schemes, i.e., $f * j=\max \left\{f_{k j} \mid k=1,2, \ldots, K\right\}$, and the negative-ideal solution is set as the minimum of all schemes, i.e., $f-j=\min \left\{f_{k j} \mid k=1,2, \ldots, K\right\}$. Then, we can obtain the gap ratio, as is described in equation (13).

$$
z_{k j}=\frac{\left(\left|f_{j}^{*}-f_{k j}\right|\right)}{\left(\left|f_{j}^{*}-f_{j}^{-}\right|\right)} .
$$

Step 2. Calculating the average gap $E_{k}$ and maximal gap $Q_{k}$ for prioritizing improvement. follows:

The general form of the $L_{p \text {-metric }}$ function is introduced as

$$
L_{k}^{p}=\left\{\sum_{j=1}^{n}\left[w_{j} \times z_{k j}\right]^{p}\right\}^{1 / p}, \quad 1 \leq p \leq \infty ; k=1,2, \ldots, k,
$$

where $w_{j}$ is the influential weight generated from the DANP. $L_{k}^{p=1}$ and $L_{k}^{p=\infty}$ are separately expressed as $E_{k}$ and $Q_{k}$, which can be calculated by equations (15) and (16):

$$
\begin{aligned}
& E_{k}=L_{k}^{p=1}=\sum_{j=1}^{n} w_{j} \times z_{k j}, \\
& Q_{k}=L_{k}^{p \longrightarrow \infty}=\max j\left\{z_{k j} \mid j=1,2, \ldots, n\right\} .
\end{aligned}
$$

The compromise solution $\min _{k} L_{p} k$ indicates that the synthesized gap should be minimized. The average gap is emphasized when $p$ is equal to one. However, $Q_{k}$ means the maximum gap of overall criteria in alternative $k$. When $p$ is infinite, the maximal gaps should be improved by the priority.

Step 3. Exporting comprehensively evaluated values of the alternatives.

$$
U_{k}=\lambda \frac{\left(E_{k}-E^{*}\right)}{\left(E^{-}-E^{*}\right)}+(1-\lambda) \frac{\left(Q_{k}-Q^{*}\right)}{\left(Q^{-}-Q^{*}\right)} .
$$

For equation (15), the best gap $E * k$ and the worst value $E-k$ is expressed as $E * k=\min _{k} E_{k}$ and $E-k=\max _{k} E_{k}$, respectively; For equation (16), the best gap $Q * k$ and the worst value $Q-k$ is separately expressed as $Q * k=\min _{k} Q_{k}$ and $Q-k=\max _{k} Q_{k}$. Furthermore, in optimal conditions, $E * k=0, Q * k=0$, and at worse, $E-k=1, Q-k=1$. Then, equation (17) can be simplified as follows:

$$
U_{k}=\lambda E_{k}+(1-\lambda) Q_{k}
$$

The range of values for $\lambda$ is zero to one. $\lambda>0.5$ means the analysis emphasizes the average gap more. $\lambda<0.5$ indicates the analysis is more concerned about the maximum gap for priority improvement. In general, we can set $\lambda=0.5$.

\section{Empirical Results}

Based on the above models, ten types of BEVs are carried out as shown in Table 1. The empirical results of the analytical process are as follows:

4.1. Building Evaluation Indicator System. The online wordof-mouth of BEVs is from the Autohome website (see https://www.autohome.com.cn/), which is a relatively wellknown auto website in China. Word-of-mouth is the key for users to express their views. On the Autohome website, the word-of-mouth data reflect vehicle attributes that users are most concerned about. Because the website has strict requirements on the opinions, all the text information is accurate and of high quality.

4.1.1. Emotional Polarity Analysis. First, emotional lexicon is extracted from the text that has been preprocessed. Table 2 shows the emotional words with high word frequency. It can be found that the word frequency of the emotional words, such as right, fine, smooth, not bad, not so dusty, high, comfortable, stable, and so on, is very high, which indicated that consumers' overall cognition of BEVs is relatively concentrated.

On the Autohome website, the overall image of a BEV is often measured in terms of the customers' satisfaction with the BEV. Then, the emotional terms of customers' satisfaction are obtained through cluster analysis, as is shown in Table 3. The overall satisfaction of customers with the BEV is measured by the emotion words that indicate emotion. $30.6 \%$ of the total number of word-of-mouth have 
TABLE 1: Details of ten types of BEVs.

\begin{tabular}{lcc}
\hline Alternatives & Vehicle types & Vehicle manufacturers \\
\hline$P 1$ & BAOJUN E100 & SGMW Company \\
$P 2$ & BAIC EU Series & BAIC BJEV Company \\
$P 3$ & Aion S & GAC NE Company \\
$P 4$ & MG EZS & SAIC Motor \\
$P 5$ & Aeolus E70 & Dongfeng Passenger Vehicle Company \\
$P 6$ & GEOMETRY A & Geely Auto Company \\
$P 7$ & BYD Yuan & BYD Company \\
$P 8$ & BESTUNE B30EV & China FAW Group Corporation \\
$P 9$ & EMGRAND EV & Geely Auto Company \\
$P 10$ & ORA R1 & Great Wall Motor Company Limited \\
\hline
\end{tabular}

TABLe 2: The emotional words with high word frequency.

\begin{tabular}{|c|c|c|c|c|c|}
\hline Emotional words & Frequency & Emotional words & Frequency & Emotional words & Frequency \\
\hline Right & 725476 & Powerful & 524895 & Low & 302589 \\
\hline Fine & 707542 & Not too bad & 524123 & Expensive & 212587 \\
\hline Smooth & 694575 & Not very good & 487256 & Pretty good & 128456 \\
\hline Not bad & 675821 & Uneconomic & 462358 & Excellent & 114753 \\
\hline Not so dusty & 658426 & Loud & 458697 & Terrible & 102475 \\
\hline High & 654895 & So-so & 458241 & Poor & 102452 \\
\hline Comfortable & 641257 & Beautiful & 458214 & Reasonable & 85426 \\
\hline Stable & 607002 & Super good & 436248 & Bad & 83856 \\
\hline Passable & 597426 & Spacious & 385462 & Insensitive & 68542 \\
\hline Noisy & 584712 & High-end & 368456 & Awful & 62147 \\
\hline Cheap & 548968 & Accurate & 325869 & Small & 56235 \\
\hline
\end{tabular}

TABLE 3: Emotional terms of customers' satisfaction.

\begin{tabular}{lc}
\hline Customers' satisfaction & Emotional words \\
\hline Practical feelings $\gg$ expectations & Super good, pretty good, excellent, superb, high, etc. \\
Practical feelings $>$ expectations & Not bad, right, fine, not so dusty, cheap, etc. \\
Practical feelings $=$ expectations & Passable, not too bad, etc. \\
Practical feelings $<$ expectations & Not very good, so-so, etc. \\
Practical feelings $\gg<<$ expectations & Loud, poor, bad, low, terrible, awful, expensive, noisy, etc. \\
\hline
\end{tabular}

customers' satisfaction far greater than customers' expectations, $27.5 \%$ of the total have customers' satisfaction greater than customers' expectations, $15 \%$ of the total have customers' satisfaction equal to customers' expectations, $10.7 \%$ of the total have customers' satisfaction less than customers' expectations, and $16.2 \%$ of the total have customers' satisfaction far less than customers' expectations.

Finally, the word-of-mouth containing the above sentiment words are calculated and scored. The actual score ranges from 1 to 5 points according to the set scoring rules (using the sentiment dictionary method, transforming and rounding the results), the scores of the word-of-mouth containing the sentiment words are obtained, and the average score containing each sentiment word is calculated (the ratio of the frequency of the sentiment word to the number of word-of-mouth containing the sentiment word). The emotional scores are shown in Table 4.

4.1.2. Topic Analysis. This study identifies the consumer concerns by using the LDA model, to discover key topics from the collected text. As is shown in Table 5, the LDA model divides keywords into five topics, including dynamics, technology, safety, comfort, and cost. Specifically, the keywords in topic 1 mainly involve maximum power, max torque, top speed, and acceleration time, which reflect the dynamics. In topic 2, the keywords mainly involve driving range, charging time, and electricity consumption, which reflect the battery technology. The keywords of topic 3 are mainly related to three aspects, curb weight, braking, and operating stability, which represent the safety of BEVs. In topic 4, the keywords mainly involve four aspects, exterior and interior, space, suspension, and seats, reflecting the comfort of BEVs. The keywords in topic 5 involve three aspects: price, incentives, and after-sales cost, which are the embodiment of the cost factor.

Through the above analysis, five major topics are obtained, which are taken as the five dimensions in the indicator system. Seventeen criteria are identified by keyword segmentation. The details of the evaluation dimensions and criteria of BEVs are shown in Table 6.

4.2. Data Collection. Based on the evaluation indicator system, two different questionnaires are designed to collect the information required for sufficient evaluation of ten BEVs. The DEMATEL questionnaire on the relationship 
TABLE 4: Average score of word-of-mouth with sentiment words.

Customers' satisfaction Emotional words

Super good, pretty good, excellent, superb, comfortable, high, etc.

Not bad, right, fine, not so dusty, etc.

Passable, not too bad, etc.

Not very good, so-so, etc.

Loud, poor, bad, low, terrible, awful, etc.

TABle 5: The word-of-mouth data analysis results.

\begin{tabular}{|c|c|}
\hline Topics & Keywords \\
\hline Topic 1: dynamics & Power, accelerate, full of power, torque, top speed, powerful, climbing \\
\hline $\begin{array}{l}\text { Topic 2: } \\
\text { technology }\end{array}$ & Charge, quick charge, economy, battery capacity, range, lithium battery, electricity consumption \\
\hline Topic 3: safety & Braking, stability, control, vehicle weight, sensitivity, steering, accurate, start smoothly \\
\hline Topic 4: comfort & $\begin{array}{l}\text { Space, seat, rear seats, seat backs, suspension, damping, fashion, high-end, face value, taillight, design, wheel, } \\
\text { dashboard, workmanship, large screen, recorder, high beams }\end{array}$ \\
\hline Topic 5: c & $\begin{array}{c}\text { Price, virtual-high, subsidies, incentives, policies, restricted licence, repair, maintenance, after-sale service, supporting } \\
\text { facilities, market ratios, cost-efficient, quality assurance }\end{array}$ \\
\hline
\end{tabular}

TABLE 6: Descriptions of the evaluation dimensions and criteria of BEVs.

\begin{tabular}{|c|c|c|c|}
\hline Dimensions & Criteria & Descriptions & Source \\
\hline \multirow{4}{*}{ Dynamics $(A)$} & Maximum power $(A 1)$ & Maximum power output that the BEVs can achieve. & {$[53,86]$} \\
\hline & Max torque $(A 2)$ & The higher the torque is, the better the vehicle acceleration. & [51] \\
\hline & Top speed $(A 3)$ & Top speed that can be driven on good road. & {$[27,30,87]$} \\
\hline & $\begin{array}{l}\text { Acceleration time } \\
\qquad(A 4)\end{array}$ & Acceleration time refers to the acceleration time of 100 kilometers. & {$[27,30,88,89]$} \\
\hline \multirow{3}{*}{$\begin{array}{l}\text { Technology } \\
(B)\end{array}$} & Driving range $(B 1)$ & $\begin{array}{l}\text { In the standards of the new European driving Cycle, the maximum mileage the } \\
\qquad \text { EVs can run without a recharge. }\end{array}$ & [90-93] \\
\hline & $\begin{array}{c}\text { Electricity } \\
\text { consumption }(B 2)\end{array}$ & Electricity consumption for 100 kilometers. & {$[27]$} \\
\hline & Charge time $(B 3)$ & $\begin{array}{c}\text { The time required to charge the battery to } 80 \% \text { of capacity using high-power } \\
\text { direct current (DC) charging. }\end{array}$ & {$[90,91,94]$} \\
\hline \multirow{3}{*}{ Safety $(C)$} & Curb weight $(C 1)$ & Empty weight is one of the most important factors to check the safety of a vehicle. & [95] \\
\hline & $\begin{array}{l}\text { Braking properties } \\
\text { (C2) }\end{array}$ & The shorter the braking distance is, the higher the safety. & {$[96,97]$} \\
\hline & $\begin{array}{l}\text { Operating stability } \\
\qquad(C 3)\end{array}$ & It is a combination of mobility and stability. & {$[61]$} \\
\hline \multirow{4}{*}{ Comfort $(D)$} & Car space $(D 1)$ & $\begin{array}{c}\text { It includes the size of the driver control space, luggage space, and passenger } \\
\text { compartment. }\end{array}$ & {$[98]$} \\
\hline & Suspension $(D 2)$ & Vibration characteristics ensure normal and comfortable driving. & [99] \\
\hline & Car seat $(D 3)$ & It includes electrically adjustable, soft, and comfortable material, etc. & {$[87]$} \\
\hline & $\begin{array}{l}\text { Exterior and interior } \\
\qquad(D 4)\end{array}$ & $\begin{array}{l}\text { Exterior involves many aspects, such as appearance and color; interior involves } \\
\text { reasonable color matching, complete and intelligent equipment, etc. }\end{array}$ & {$[61,100]$} \\
\hline \multirow{3}{*}{ Cost $(E)$} & Price $(E 1)$ & Whether the price is within the acceptable range. & {$[101-103]$} \\
\hline & Incentives (E2) & It includes purchase tax, subsidies, etc. & [104-106] \\
\hline & After-sales cost $(E 3)$ & It includes vehicle repairs, maintenance, and other expenses. & {$[4,12]$} \\
\hline
\end{tabular}

between dimensions and criteria is emailed to 8 experts who are proficient in the automobile industry and have several years of experience in the BEVs field. Moreover, experts' professional and practical experience can strongly support personal interviews and questionnaires. Experts can use a five-point scale ranging from $0-4$ to grade mutual influences based on pairwise comparisons [45]. Then we collect the experts' results and compute the average scores of all criteria to form the initial direct-effect matrix, as is shown in Table 7. The statistical significance confidence of scores by experts is
95.13\% (greater than 95\%; i.e., the gap error is only $4.87 \%$, or $<5 \%$ ), which indicates consistent responses.

The modified VIKOR questionnaire is distributed to customers who have bought BEVs or intend to buy BEVs to score the criteria, on an eleven-point scale ranging from $0-10$. Of the 550 questionnaires distributed, 540 valid questionnaires are obtained. The internal consistency of customer ratings is tested using Cronbach's alpha [107]. The null hypothesis of the scores associated with each BEV is defined as no difference between customer ratings. The 
alternative hypothesis assumes that the scores are different. The Cronbach's alpha values related to these ten hypotheses are $0.894,0.882,0.930,0.855,0.838,0.823,0.825,0.802$, 0.750 , and 0.835 , respectively. The null hypothesis is significant. It is hoped that this study can help the government departments and automobile enterprises' decision-makers to effectively improve customers' purchasing decisions, thereby enhancing the BEV's development and competitiveness.

\subsection{Estimating the Relationships among Dimensions and} Criteria. The DEMATEL technique is applied to obtain the cause-effect relationships and to construct the INRM among dimensions and criteria. According to the responses from 7 experts, the direct effect $17 \times 17$ matrix $G=\left[a_{i j}\right]$ is constructed in Table 7 . The normalized direct-influence matrix $X$ in Table 8 is derived by equations (1)-(3). The total influence matrix $T_{c}$ of the criteria and matrix $T_{D}$ of the dimensions are separately listed in Tables 9-10. Furthermore, the $\left(r_{i}+s_{i}\right)$ and $\left(r_{i}-s_{i}\right)$ values of indicators can be obtained from the total influence matrix, as is shown in Table 11. The implication of $\left(r_{i}+s_{i}\right)$ presents the intensity of the influence that the $i$ th criterion plays in the problem, and $\left(r_{i}-s_{i}\right)$ presents the size of the $i$ th criterion's direct impact on others. When $\left(r_{i}-s_{i}\right)$ is positive, ith criterion influences other criteria. On the contrary, if $\left(r_{i}-s_{i}\right)$ is negative, ith criterion is influenced by other criteria. The INRM is drawn with $\left(r_{i}+s_{i}\right)$ as the horizontal axis and $\left(r_{i}-s_{i}\right)$ as the vertical axis, reflecting the cause-and-effect relationships between dimensions and criteria as shown in Figure 2.

As shown in Table 11, the five dimensions can be prioritised as $E>A>B>C>D$ based on the $\left(r_{i}+s_{i}\right)$ values, where the cost $(E)$ has the highest impact intensity, with a value of 0.402 . The comfort $(D)$ is the most vulnerable in its influence, with a value of 0.154 . The influential relationship $\left(r_{i}-s_{i}\right)$ indicates that safety $(C)$, technology $(B)$, dynamics $(A)$, and comfort $(D)$ have the highest direct influence on the other dimensions in relationship studies, with the values of $0.084,0.062,0.058$, and 0.052 . On the contrary, cost $(E)$ has the lowest negative value of -0.256 , which is easily affected by other dimensions. Hence, based on the causal relationships derived in Figure 2, the safety $(C)$ affects technology $(B)$, dynamics $(A)$, and comfort $(D)$, whereas cost $(E)$ is influenced by all other dimensions.

The network relationship between criteria under each dimension can be shown in Figure 2 . The $\left(r_{i}+s_{i}\right)$ and $\left(r_{i}-s_{i}\right)$ are shown in Table 11. Overall, from the $\left(r_{i}+s_{i}\right)$ values, maximum power $(A 1)$ is considered the most important criterion of all criteria, with the value of 0.397 . From the $\left(r_{i}-s_{i}\right)$ values, max torque $(A 2)$, driving range (B1), curb weight $(C 1)$, suspension (D2), and incentives (E2) have a greater influence on the other criteria in the individual dimensions. According to Figure 2, specifically, in the dynamics $(A)$ dimension, max torque $(0.110)$ and maximum power (0.085) have the strongest influence on max speed $(-0.056)$ and acceleration time $(-0.019)$. This indicates that max torque should be improved first to prompt customer purchase intention. In the technology $(B)$ dimension, the driving range (0.019) directly influences the remaining criteria, including electricity consumption (-0.009) and charge time $(-0.011)$. Thus, it is important to achieve a longer driving range to ease consumers' range anxiety, thereby affecting the degree of purchase. Automobile enterprises should increase technological investment and give priority for expanding driving. Under the same circumstances, consumers usually choose new energy vehicles with a high range [54]. In terms of safety $(C)$ dimension, curb weight (0.194) exerts a direct effect on the other criteria, including braking properties $(-0.093)$ and operating stability $(-0.101)$. Therefore, lightweight technology should be supported and promoted to reduce curb weight and thus improve the safety of BEVs. In the comfort $(D)$ dimension, the criterion of suspension (0.048) and car seat (0.017) strongly influence exterior and interior $(-0.016)$, and car space $(-0.050)$. Thus, optimizing the suspension to improve operating comfort is the most influential way to encourage a customer to purchase new vehicles. In the cost $(E) \mathrm{di}$ mension, incentives (0.072) exert a direct effect on the remaining criteria, including price $(-0.033)$ and after-sales cost $(-0.039)$. Therefore, incentives play the most important role in consumers' decisions. The general improvement priorities can be sequenced as E2, E1, and E3.

4.4. Determining the Influence Weights. After identifying the relationships among indicators through the DEMATEL technique, the influence weights of those indicators can be obtained by the DANP method. Initially, the unweighted super-matrix $W_{c}$ in Table 12 can be derived by equation (11). The weighted super-matrix $W * c$ in Table 13 can be obtained using equation (12). Finally, the weight of each criterion is acquired by limiting the power of the weighted super-matrix.

According to the influence weights shown in Table 14, in terms of dimensions, the cost $(0.400)$ is ranked as the most important weight, while the comfort (0.062) is ranked as the least important one. Based on the influence weights (global weights) associated with seventeen criteria, empirical results reveal that price $(E 1)$, incentives (E2), and after-sales cost (E3) are ranked as the top criteria. Concretely, price gains the highest point of 0.191, followed by incentives (0.106) and after-sales cost (0.103). Moreover, the influence weights of suspension (0.010), car seat (0.010), exterior, and interior (0.009) are relatively low, which means that these criteria have the least impact.

\subsection{Obtaining the Selection Strategies and Optimal Path.} This study aims to propose the most effective strategies to improve customers' decisions for BEVs in China. In this section, the Modified VIKOR method is employed to evaluate ten models based on the opinion of customers. The range of $f_{i k}$ is defined from 0 to 10 , where 0 is the worst level, and 10 is the desired level in the evaluation. By introducing the relative weight versus each criterion, the average gap $E_{k}$ and maximal gap $Q_{k}$ is derived. $U_{k}$ is also derived by setting $v$ as 0.5 . Thus, each BEV could be evaluated and ranked, and the results are shown in Table 15. The key to solving the problem can be identified according to this integrated index from the dimension perspective or the criteria perspective. 


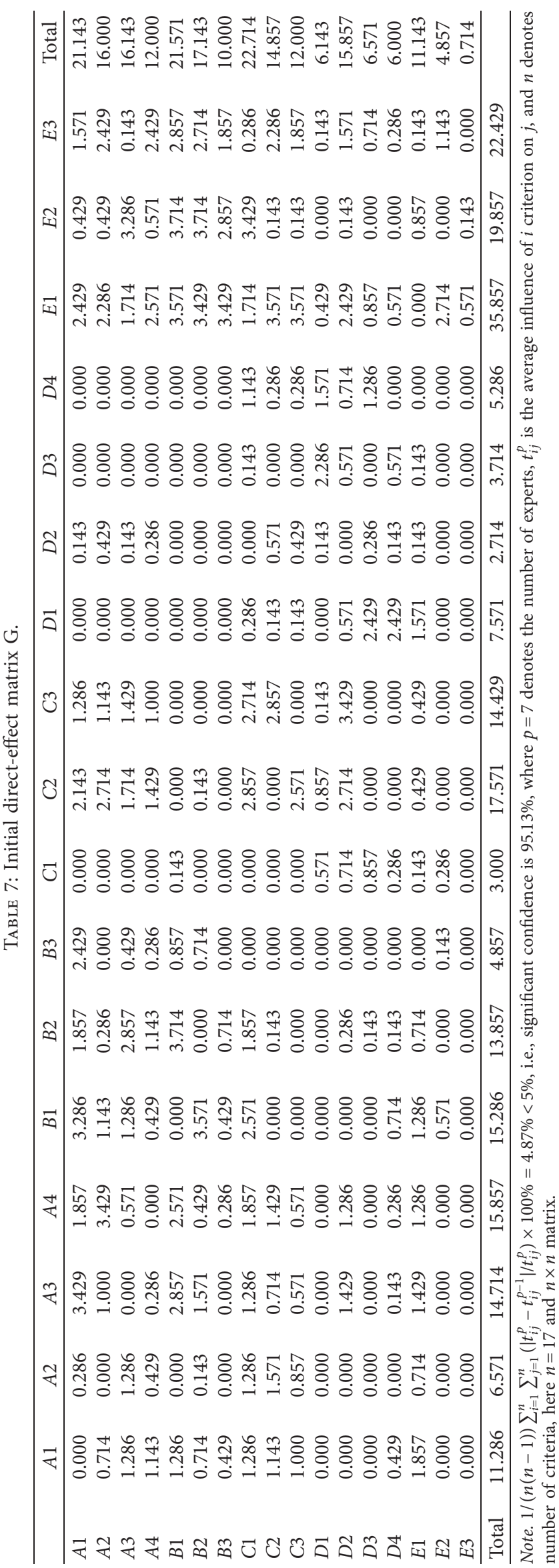


TABLE 8: The normalized direct-influence matrix $X$.

\begin{tabular}{|c|c|c|c|c|c|c|c|c|c|c|c|c|c|c|c|c|c|}
\hline & $A 1$ & $A 2$ & A3 & $A 4$ & $B 1$ & $B 2$ & B3 & $C 1$ & $C 2$ & C3 & $D 1$ & D2 & D3 & $D 4$ & $E 1$ & $E 2$ & E3 \\
\hline$A 1$ & 000 & 008 & 096 & 052 & 092 & 052 & 8 & . 000 & 060 & 03 & 000 & 004 & .000 & .000 & 06 & .01 & 0.0 \\
\hline$A 2$ & & & & & & & & & & & & & & & & & \\
\hline$A 3$ & .036 & 03 & .000 & .016 & & & & & & & & & & & & & 04 \\
\hline$A 4$ & .032 & 012 & .008 & .000 & 0.012 & .032 & .008 & 0.000 & 040 & & & & & & & & 0.068 \\
\hline$B 1$ & .036 & .000 & .080 & 0.072 & 0.000 & & & 0.004 & 0.000 & & & & & .000 & & & 80 \\
\hline$B 2$ & & & & & & & & & & & & & & & & & \\
\hline B3 & & & & & & & & & & & & & & & & & \\
\hline$C 1$ & c & & & 0.052 & & & & & & & & & & & & & 0.008 \\
\hline 22 & & & & & & & & & & & & & & & & & \\
\hline C3 & 0 & c & 0 & & & & & & & & & & & & & & \\
\hline$D 1$ & & & & & & & & & & & & & & & & & 004 \\
\hline D2 & 000 & & & & & & & & & & & & & & & & 0.044 \\
\hline D3 & & & & & & & & & & & & & & & & & \\
\hline D4 & 0.012 & & 004 & 0.008 & & & & & & & & & & & & & 0.008 \\
\hline$E 1$ & 0.052 & .020 & 0.040 & 0.036 & & & & & & & & & & & & & 0.004 \\
\hline$E 2$ & 0.000 & .000 & 0.000 & 0.000 & 0.016 & 0.000 & 0.004 & 0.008 & 0.000 & 0.000 & 0.000 & 0.000 & 0.000 & 0.000 & 0.076 & & 0.032 \\
\hline E3 & 0.000 & 0.000 & 0.000 & 0.000 & 0.000 & 0.000 & 0.000 & 0.000 & 0.000 & 0.000 & 0.000 & 0.000 & 0.000 & 0.000 & 0.016 & 0.004 & 0.000 \\
\hline
\end{tabular}

TABLE 9: The total influence matrix of criteria.

\begin{tabular}{|c|c|c|c|c|c|c|c|c|c|c|c|c|c|c|c|c|c|c|}
\hline & $A 1$ & $A 2$ & $A 3$ & A4 & $B 1$ & $B 2$ & B3 & $C 1$ & $C 2$ & C3 & $D 1$ & D2 & D3 & D4 & E1 & $E 2$ & E3 & $r_{i}$ \\
\hline$A 1$ & .024 & 021 & 120 & 076 & 114 & .082 & 076 & 002 & 078 & .053 & 006 & 008 & 0.001 & .002 & .128 & 0.055 & .082 & 0.241 \\
\hline$A 2$ & 0.037 & .011 & .045 & 112 & 0.045 & 0.025 & 0.006 & .001 & 092 & & & & & & & & .094 & 0.204 \\
\hline$A 3$ & 0.051 & .044 & .021 & 0.036 & 0.058 & 0.094 & 0.020 & 0.002 & .063 & 0.052 & .005 & 007 & .001 & .001 & 0.096 & .116 & .036 & 0.152 \\
\hline$A 4$ & 0.04 & & 023 & & & & & & & & & & & & & & & \\
\hline$B 1$ & 0 & 0 & 0.101 & & & & 0 & & & & & & & & & & & \\
\hline$B 2$ & 0.036 & 011 & .064 & 0.030 & 0.116 & 0.023 & 0.027 & 002 & 0.014 & & & & & & & & & 0.166 \\
\hline$B 3$ & 0.020 & 003 & .010 & .016 & 0.023 & 0.027 & 0.003 & 0.0 & 0.005 & 0.00 & & & 0.001 & & & 0.090 & 62 & 0.053 \\
\hline$C 1$ & 0.05 & ( & 063 & & & & & & & & & & & & & & & 199 \\
\hline$C 2$ & 0.047 & 052 & 036 & & & & & & & & & & & & & & & 0.113 \\
\hline C3 & 0.041 & & 0.030 & & & & & & & & & & & & & & & 0.099 \\
\hline$D 1$ & 0.004 & 0.003 & 0.004 & 0.004 & 0.004 & 0.003 & 0.001 & 0.018 & 0.028 & 0.009 & 0.009 & 0.005 & 0.065 & 0.048 & 0.021 & 0.004 & 0.010 & 0.127 \\
\hline D2 & 0.017 & 012 & 053 & 051 & 0.013 & 0.020 & 0.003 & 0.02 & & 0.11 & 0.024 & & 0.0 & & & .019 & .066 & 0.071 \\
\hline D3 & 0.004 & 0.002 & 0.004 & 0.004 & 0.00 & 0.007 & 0.001 & .026 & 0.006 & 0.004 & 0.073 & & .006 & 040 & & .005 & .024 & 0.127 \\
\hline$D 4$ & 0.016 & 0.002 & 0.010 & 0.013 & 0.025 & 0.010 & 0.002 & 0.010 & 0.006 & 0.004 & 0.071 & 0.005 & 0.021 & 0.004 & 0.026 & 0.007 & 0.014 & 0.101 \\
\hline$E 1$ & 0.062 & 0.026 & 0.055 & 0.050 & 0.051 & & 0.007 & & & 0.022 & & & 0.007 & & & 0.042 & 0.024 & 0.097 \\
\hline$E 2$ & 0.006 & & .006 & & & & & & & & & & & & & .007 & .036 & 0.125 \\
\hline E3 & 0.001 & 0.000 & 0.001 & 0.001 & 0.001 & 0.001 & 0.000 & 0.0 & 0.000 & 0.000 & 0.0 & 0.0 & 0.000 & 0.000 & 0.017 & 0.005 & 0.001 & 0.022 \\
\hline$s_{i}$ & 0.156 & 0.094 & 0.208 & 0.236 & 0.169 & 0.175 & 0.064 & 0.005 & 0.207 & 0.200 & 0.177 & 0.024 & 0.110 & 0.116 & 0.130 & 0.054 & 0.061 & \\
\hline
\end{tabular}

Table 10: The total influence matrix of dimension.

\begin{tabular}{lcccccc}
\hline Dimension & $A$ & $B$ & $C$ & $D$ & $E$ & $r_{i}$ \\
\hline$A$ & 0.043 & 0.050 & 0.040 & 0.005 & 0.079 & 0.217 \\
$B$ & 0.037 & 0.045 & 0.008 & 0.002 & 0.206 \\
$C$ & 0.048 & 0.027 & 0.046 & 0.012 & 0.081 \\
$D$ & 0.013 & 0.008 & 0.028 & 0.027 & 0.028 & 0.214 \\
$E$ & 0.018 & 0.014 & 0.008 & 0.006 & 0.027 & 0.073 \\
\hline$s_{i}$ & 0.159 & 0.144 & 0.129 & 0.051 & 0.329 \\
\hline
\end{tabular}

The order of priority for achieving the desired level can be determined by the weights of the performance values, from high to low, and the gap values, from high to low.

As indicated in Table 15, Aion S (P3) produced by GAC NE company presents the smallest gap (0.276) and therefore ranks first, followed by the BAIC EU Series (P2; 0.296), MG EZS (P4; 0.297), BESTUNE B30EV (P8; 0.304), GEOMETRY
A (P6; 0.305), EMGRAND EV (P9; 0.340), Aeolus E70 (P5; $0.341)$, BYD Yuan $(P 7 ; 0.344)$, ORA R1 (P10; 0.471$)$, and BAOJUN E100 $(P 1 ; 0.694)$ in this regard. Integration of the scores of Aion S (P3) further demonstrates that the gap for the dynamics $(A)$ dimension is 0.191 and that for the suspension (D2) criterion is 0.367 , constituting the largest gaps, which Aion $S$ should improve as a priority. The integration 
TABLE 11: Sum of influences given/received on dimensions/criteria.

\begin{tabular}{|c|c|c|c|c|}
\hline Criteria & $r_{i}$ & $s_{i}$ & $r_{i}+s_{i}$ & $r_{i}-s_{i}$ \\
\hline Dynamics $(A)$ & 0.217 & 0.159 & 0.376 & 0.058 \\
\hline Maximum power $(A 1)$ & 0.241 & 0.156 & 0.397 & 0.085 \\
\hline Max torque $(A 2)$ & 0.204 & 0.094 & 0.298 & 0.110 \\
\hline Max speed $(A 3)$ & 0.152 & 0.208 & 0.361 & -0.056 \\
\hline Acceleration time $(A 4)$ & 0.098 & 0.236 & 0.334 & -0.139 \\
\hline Technology $(B)$ & 0.206 & 0.144 & 0.351 & 0.062 \\
\hline Driving range (B1) & 0.189 & 0.169 & 0.358 & 0.019 \\
\hline Electricity consumption (B2) & 0.166 & 0.175 & 0.341 & -0.009 \\
\hline Charge time $(B 3)$ & 0.053 & 0.064 & 0.116 & -0.011 \\
\hline Safety $(C)$ & 0.214 & 0.129 & 0.343 & 0.084 \\
\hline Curb weight $(C 1)$ & 0.199 & 0.005 & 0.205 & 0.194 \\
\hline Braking properties $(C 2)$ & 0.113 & 0.207 & 0.320 & -0.093 \\
\hline Operating stability $(C 3)$ & 0.099 & 0.200 & 0.299 & -0.101 \\
\hline Comfort $(D)$ & 0.103 & 0.051 & 0.154 & 0.052 \\
\hline Car space $(D 1)$ & 0.127 & 0.177 & 0.304 & -0.050 \\
\hline Suspension (D2) & 0.071 & 0.024 & 0.095 & 0.048 \\
\hline Car seat $(D 3)$ & 0.127 & 0.110 & 0.238 & 0.017 \\
\hline Exterior and interior $(D 4)$ & 0.101 & 0.116 & 0.217 & -0.016 \\
\hline Cost $(E)$ & 0.073 & 0.329 & 0.402 & -0.256 \\
\hline Price $(E 1)$ & 0.097 & 0.130 & 0.227 & -0.033 \\
\hline Incentives $(E 2)$ & 0.125 & 0.054 & 0.179 & 0.072 \\
\hline After-sales cost $(E 3)$ & 0.022 & 0.061 & 0.083 & -0.039 \\
\hline
\end{tabular}

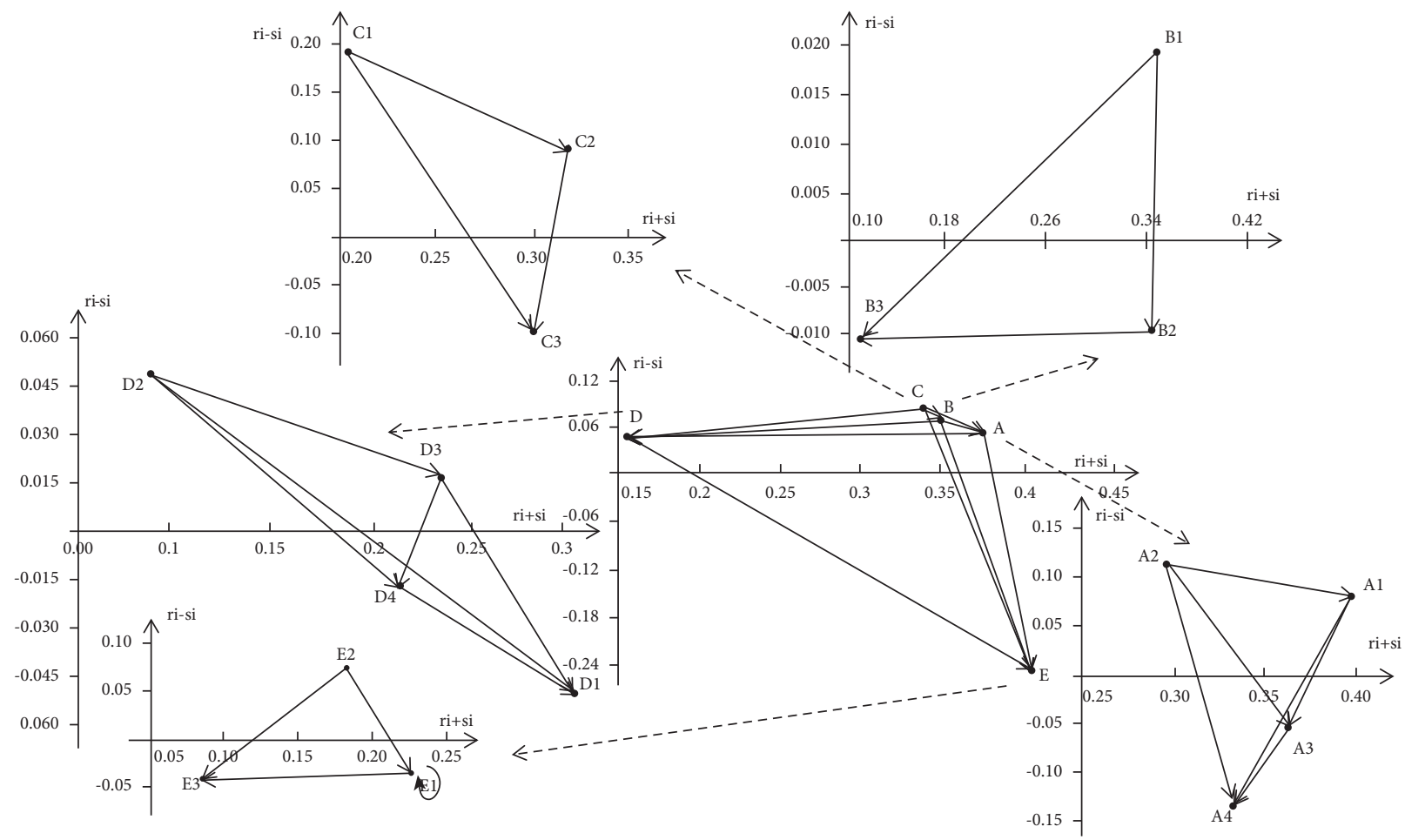

FIgURE 2: The INRM of each dimension and criterion.

of the scores of the BAIC EU Series (P2) in the DANP shows that the gap of the safety $(C)$ dimension is 0.267 and that of the alliance with operating stability (C3) criterion is 0.383 , constituting the largest gaps, which the BAIC EU Series should improve as a priority. The integration of the scores of BAOJUN E100 (P1) in the DANP shows that the gap of the comfort $(D)$ dimension is 0.467 and that of the charge time
(B3) criterion is 1.000 , constituting the largest gaps, which BAOJUN E100 should improve as a priority. The integration of the scores of MG EZS (P4) in the DANP shows that the gap of the vehicle comfort $(D)$ dimension is 0.276 and that of the suspension (D2) criterion is 0.367 , constituting the largest gaps, which MG EZS should improve as a priority. The integration of the scores of Aeolus E70 (P5) in the 
TABLe 12: The unweighted super-matrix Wc.

\begin{tabular}{|c|c|c|c|c|c|c|c|c|c|c|c|c|c|c|c|c|c|}
\hline & & $A 1$ & $A 2$ & $A 3$ & $A 4$ & $B 1$ & $B 2$ & B3 & $C 2$ & C3 & D1 & D2 & D3 & D4 & $E 1$ & $E 2$ & E3 \\
\hline \multirow{4}{*}{$A$} & $A 1$ & & & & & & & & & & & & & & & & .321 \\
\hline & $A 2$ & & & & & & & & & & & & & & & & \\
\hline & $A 3$ & .497 & 0.219 & 0.141 & 0.231 & 0.397 & & & & & & & & & & & .287 \\
\hline & $A 4$ & & & & & & & & & & & & & & & & \\
\hline \multirow{3}{*}{$B$} & $B 1$ & & & & רקי & & & & & & & & & & & & 0.551 \\
\hline & $B 2$ & & & & & & & & & & & & & & & & .365 \\
\hline & $B 3$ & 0 & 0.07 & & $0.1 C$ & 0.177 & & & & & & & & & & & 0.085 \\
\hline \multirow{3}{*}{$C$} & $C 1$ & & & & & & & & & & & & & & & & 0.135 \\
\hline & $C 2$ & & & & & & & & & & & & & & & & 469 \\
\hline & C3 & 0 & 0 & 0 & 0.42 & 0.36 & 0.33 & 0.3 & & & & & & & & & .396 \\
\hline & $D 1$ & & & & & & & & & & & & & & & & \\
\hline & D2 & 0.463 & & & & 0.220 & & & & & & & & & & & 0.099 \\
\hline & D3 & 0.064 & & & & & & & & & & & & & & & 0.115 \\
\hline & D4 & 0.093 & 0.073 & & 0.069 & 0.072 & 0.062 & & & & & & & & & & 0.049 \\
\hline \multirow{3}{*}{ 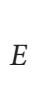 } & $E 1$ & & & & & & & & & & & & & & & & 0.763 \\
\hline & $E 2$ & & & & & & & & & & & & & & & & 0.213 \\
\hline & E3 & 0.309 & 0.414 & 0.144 & 0.396 & 0.276 & 0.271 & 0.234 & 0.362 & 0.329 & 0.280 & 0.346 & 0.393 & 0.306 & 0.248 & 0.288 & 0.024 \\
\hline
\end{tabular}

Table 13: The weighted super-matrix $W * c$.

\begin{tabular}{|c|c|c|c|c|c|c|c|c|c|c|c|c|c|c|c|c|c|c|}
\hline & & $A 1$ & $A 2$ & $A 3$ & $A 4$ & $B 1$ & $B 2$ & B3 & $C 1$ & $C 2$ & C3 & $D 1$ & D2 & D3 & D4 & $E 1$ & $E 2$ & E3 \\
\hline \multirow{4}{*}{$A$} & $A 1$ & 0.020 & .036 & 0.067 & 0.088 & 0.039 & 0.046 & 0.074 & 0.053 & 0.055 & 0.068 & 0.034 & 0.016 & 0.034 & 0.048 & 0.080 & 0.073 & 0.079 \\
\hline & $A 2$ & 0.017 & 0.010 & 0.057 & 0.038 & 0.007 & 0.013 & 0.012 & 0.044 & 0.061 & 0.054 & 0.023 & 0.011 & 0.018 & 0.006 & 0.033 & 0.030 & 0.033 \\
\hline & $A 3$ & 0.099 & 0.044 & 0.028 & 0.046 & 0.071 & 0.081 & 0.036 & 0.057 & 0.042 & 0.050 & 0.030 & 0.049 & 0.035 & 0.030 & 0.071 & 0.075 & 0.071 \\
\hline & $A 4$ & 0.063 & 0.109 & 0.047 & 0.027 & 0.062 & 0.039 & 0.057 & 0.071 & 0.067 & 0.052 & 0.037 & 0.047 & 0.037 & 0.039 & 0.064 & 0.070 & 0.064 \\
\hline \multirow{3}{*}{$B$} & $B 1$ & 0.097 & 0.138 & 0.078 & 0.074 & 0.036 & 0.153 & 0.095 & 0.067 & 0.053 & 0.059 & 0.040 & 0.027 & 0.030 & 0.051 & 0.105 & 0.130 & 0.107 \\
\hline & $B 2$ & 0.069 & 0.075 & 0.126 & 0.119 & 0.145 & 0.031 & 0.112 & 0.053 & 0.057 & 0.049 & 0.030 & 0.042 & 0.042 & 0.020 & 0.074 & 0.033 & 0.071 \\
\hline & B3 & 0.064 & 0.017 & 0.026 & 0.037 & 0.039 & 0.036 & 0.013 & 0.007 & 0.017 & 0.019 & 0.005 & 0.006 & 0.004 & 0.004 & 0.015 & 0.032 & 0.016 \\
\hline \multirow{3}{*}{ C } & $C 1$ & 0.002 & 0.002 & 0.003 & 0.002 & 0.006 & 0.003 & 0.005 & 0.003 & 0.003 & 0.003 & 0.091 & 0.026 & 0.195 & 0.142 & 0.011 & 0.063 & 0.014 \\
\hline & $C 2$ & 0.108 & 0.119 & 0.099 & 0.104 & 0.017 & 0.021 & 0.018 & 0.110 & 0.039 & 0.181 & 0.138 & 113 & 0.045 & 079 & 0.051 & 0.023 & 0.050 \\
\hline & C3 & 0.073 & 0.063 & 0.082 & 0.078 & 0.013 & 0.012 & 0.014 & 0.101 & 0.172 & 0.031 & 0.044 & 0.134 & 0.033 & 0.052 & 0.043 & 0.020 & 0.042 \\
\hline \multirow{4}{*}{$D$} & $D 1$ & 0.008 & & & & & & & & & & 18 & & & & 0.058 & & .058 \\
\hline & D2 & 0.010 & 0.014 & 0.010 & 0.012 & 0.002 & 0.002 & 0.001 & 0.005 & 0.025 & 0.022 & 0.011 & 0.016 & 0.018 & 0.013 & 0.008 & 0.008 & 0.008 \\
\hline & D3 & 0.001 & 0.001 & 0.001 & 0.001 & 0.001 & 0.001 & 0.001 & 0.005 & 0.002 & 0.002 & 0.133 & 0.067 & 0.011 & 0.053 & 0.009 & 0.009 & 0.009 \\
\hline & D4 & 0.002 & 0.002 & 0.002 & 0.001 & 0.001 & 0.001 & 0.001 & 0.031 & 0.013 & 0.014 & 0.097 & 0.087 & 0.082 & 0.011 & 0.004 & 0.007 & 0.004 \\
\hline \multirow{3}{*}{$E$} & $E 1$ & 0.176 & 0.166 & 0.142 & 0.169 & 0.207 & 0.204 & 0.236 & 0.148 & 0.214 & 0.228 & 0.165 & 0.149 & 0.140 & 0.148 & 0.119 & 0.245 & 0.285 \\
\hline & $E 2$ & 0.076 & & & 0.052 & & & & & 0.028 & 0.027 & 0.029 & 0.027 & 0.024 & 0.039 & 0.161 & 0.021 & 0.079 \\
\hline & E3 & 0.113 & 0.151 & 0.053 & 0.145 & 0.153 & 0.150 & 0.129 & 0.065 & 0.137 & 0.124 & 0.075 & 0.093 & 0.106 & 0.082 & 0.093 & 0.107 & 0.009 \\
\hline
\end{tabular}

TABLE 14: Influential weights of criteria based on DANP.

\begin{tabular}{|c|c|c|}
\hline Dimensions/Criteria & Local Weights & Global Weights \\
\hline Dynamics (A) & 0.214 & - \\
\hline Maximum power $(A 1)$ & 0.289 & 0.062 \\
\hline Max torque $(A 2)$ & 0.143 & 0.031 \\
\hline Max speed $(A 3)$ & 0.293 & 0.063 \\
\hline Acceleration time $(A 4)$ & 0.274 & 0.059 \\
\hline Technology (B) & 0.190 & - \\
\hline Driving range $(B 1)$ & 0.479 & 0.091 \\
\hline Electricity consumption (B2) & 0.388 & 0.074 \\
\hline Charge time $(B 3)$ & 0.133 & 0.025 \\
\hline Safety $(C)$ & 0.134 & - \\
\hline Curb weight $(C 1)$ & 0.139 & 0.019 \\
\hline Braking properties $(C 2)$ & 0.478 & 0.064 \\
\hline Operating stability $(C 3)$ & 0.383 & 0.051 \\
\hline Comfort (D) & 0.062 & - \\
\hline Car space $(D 1)$ & 0.527 & 0.032 \\
\hline Suspension (D2) & 0.156 & 0.010 \\
\hline Car seat $(D 3)$ & 0.163 & 0.010 \\
\hline Exterior and interior $(D 4)$ & 0.154 & 0.009 \\
\hline Cost $(\mathrm{E})$ & 0.400 & - \\
\hline Price $(E 1)$ & 0.477 & 0.191 \\
\hline Incentives $(E 2)$ & 0.265 & 0.106 \\
\hline After-sales cost (E3) & 0.258 & 0.103 \\
\hline
\end{tabular}




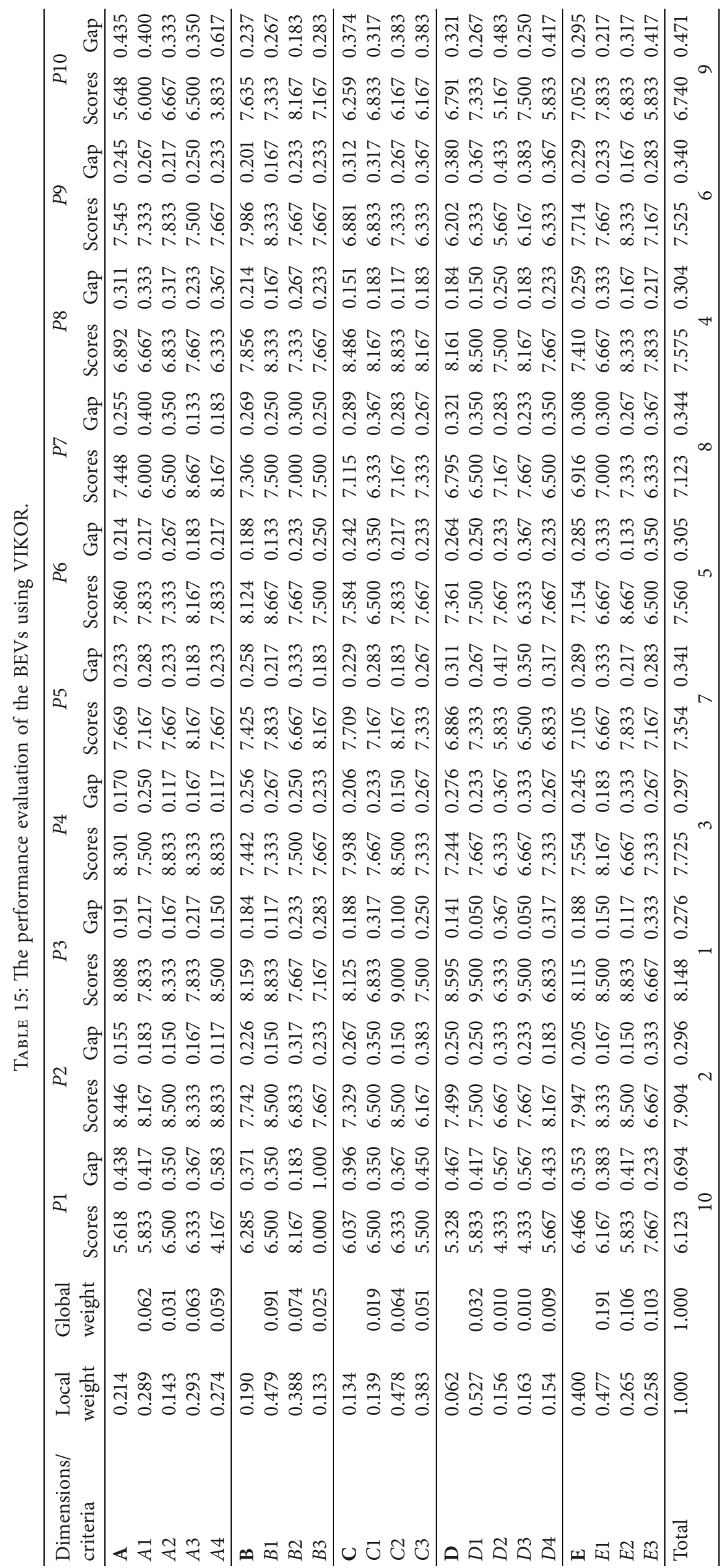


TABLE 16: The results of the two MCDM methods.

\begin{tabular}{|c|c|c|c|c|}
\hline \multirow{2}{*}{ Alternatives } & \multicolumn{2}{|c|}{ DANP-VIKOR } & \multicolumn{2}{|c|}{ CRITIC-VIKOR } \\
\hline & $U_{k}$ & Rank & $U_{k}$ & Rank \\
\hline$P 1$ & 0.694 & 10 & 0.726 & 10 \\
\hline$P 2$ & 0.296 & 2 & 0.295 & 2 \\
\hline$P 3$ & 0.276 & 1 & 0.284 & 1 \\
\hline$P 4$ & 0.297 & 3 & 0.300 & 4 \\
\hline P5 & 0.341 & 7 & 0.340 & 6 \\
\hline$P 6$ & 0.305 & 5 & 0.305 & 5 \\
\hline$P 7$ & 0.344 & 8 & 0.345 & 7 \\
\hline$P 8$ & 0.305 & 4 & 0.299 & 3 \\
\hline$P 9$ & 0.340 & 6 & 0.353 & 8 \\
\hline$P 10$ & 0.471 & 9 & 0.478 & 9 \\
\hline
\end{tabular}

DANP showed that the gap of the comfort $(D)$ dimension is 0.311 and that of the alliance with suspension (D2) criterion is 0.417 , constituting the largest gaps, which Aeolus E70 should improve as a priority. The integration of the scores of GEOMETRY A (P6) in the DANP shows that the gap of the cost $(E)$ dimension is 0.285 and that of the car seat $(D 3)$ criterion is 0.367 , constituting the largest gaps, which GEOMETRY A should improve as a priority. Integration of the scores of BYD Yuan (P7) in the DANP showed that the gap of the comfort $(D)$ dimension is 0.276 and that of the maximum power $(A 1)$ criterion is 0.400 , constituting the largest gaps, which BYD Yuan should improve as a priority. The integration of the scores of BESTUNE B30EV $(P 8)$ in the DANP shows that the gap of the dynamics $(A)$ dimension is 0.311 and that of the alliance with acceleration time $(A 4)$ criterion is 0.367 , constituting the largest gaps, which BESTUNE B30EV should improve as a priority. The integration of the scores of EMGRAND EV (P9) in the DANP shows that the gap of the vehicle comfort $(D)$ dimension is 0.380 and that of the suspension (D2) criterion is 0.433 , constituting the largest gaps, which EMGRAND EV should improve as a priority. The integration of the scores of ORA R1 (P10) in the DANP shows that the gap of the dynamics $(A)$ dimension is 0.435 and that of the acceleration time (A4) criterion is 0.617 , constituting the largest gaps, which ORA R1 should improve as a priority. Furthermore, the gap values obtained by the customers reveal that improvement priority schemes are unique and comprehensive for each separate dimension as well as for the overall range of criteria. Decision-makers in government departments and automobile enterprises can easily understand the gaps where improvements are prioritised.

\section{Discussion}

The study uses fine-grained sentiment analysis and MCDM model to explore the BEVs from the customers' point of view based on five dimensions, namely, safety, technology, dynamics, comfort, and cost. The LDA model based on finegrained sentiment analysis has been applied to obtain dimensions and criteria based on the word-of-mouth data. The DANP method combining the DEMATEL technique with ANP has been used to create an INRM to identify the causal relationship and compute the influence weights of all indicators. The Modified VIKOR is not only used to rank and determine selection strategies but also to propose the optimized path for ten BEVs.

The empirical results are discussed as follows: First, using the LDA model based on fine-grained sentiment analysis, the comprehensive evaluation indicator system is constructed, including five dimensions and seventeen criteria. According to the DEMATEL cause-and-effect model, the interrelationships between each dimension and criterion are determined by INRM. In Figure 2, the degree of the dimension effect indicates that improvement priorities should be established in the following order: safety, technology, dynamics, comfort, and cost. The results further illustrate that the decision-makers should improve safety first because it has the greatest immediate network effect on the other dimensions. The structural design, materials used in collision sites, safety equipment, and other aspects may cause accidents [108, 109], such as battery explosions and physical damages [57]. So, most people are concerned about safety when driving BEVs [58]. The findings also imply that a full understanding of the relationships among dimensions can enable automobile companies to grasp the main direction of the future revolution, thus enhancing consumers' recognition and enthusiasm for BEVs.

Second, after describing the dimensions, the study also discusses the criterion considered in each dimension. They provide a higher-level mode for the improvement of $\mathrm{BEV}$ attributes [110]. In terms of the results for the safety $(C)$ dimension, consumers are more concerned with the curb weight of BEVs. Combining lightweight designs with BEVs can further reduce environmental impacts [52]. In addition, the application of lightweight materials in the BEVs can improve functionality and safety [111]. Moreover, details on the causal relationship between technology, dynamics, comfort, and cost can also be derived from Figure 2. Each of the evaluation dimensions and criteria play an essential role in customers' choices of BEVs. Therefore, relevant departments should evaluate all the dimensions and criteria for promoting customers' attitudes and willingness. The subsequent evaluation model can be used for the automobile industry in China.

Third, the study uses the DANP to confirm the weight of the 17 influential criteria. As shown in Table 14, price (E1) is the largest relative weight of seventeen criteria with the value 
TABle 17: Optimal path.

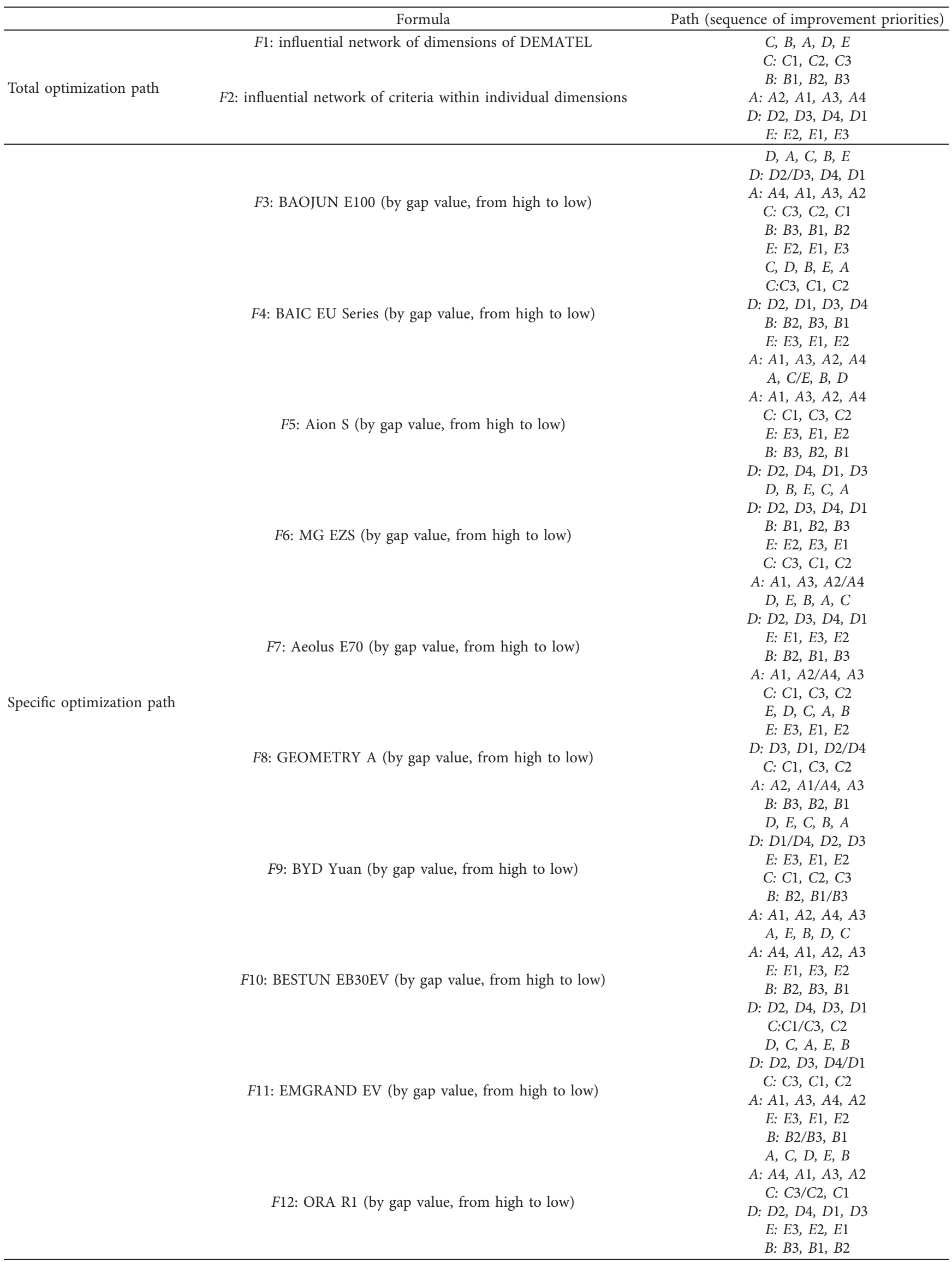


of 0.191, which indicates that the price of BEVs is the most important criterion that affects the customers' decision. Generally, the cost of BEVs is higher than that of Internal Combustion Engine Vehicles (ICEVs), which is mainly due to the high research and development (R\&D) expense and production costs, especially batteries. Hence, in addition to technology improvements, automakers can develop dedicated platforms and modular production platforms for BEVs to reduce costs as much as possible. The lowest priority is exterior and interior (0.009). Consequently, the design of the exterior and interior has the least impact on consumers' decisions. The results indicate that the priority of criterion improvement from top to bottom and the improvement of the most influential criteria would provide the largest effects. It is possible that improving different criteria will strongly influence the results directly and indirectly, and improving the most influential criteria provides the most substantial effects.

Fourth, the comparison results of ten BEVs in Table 15 show that Aion S (P3) is the best choice. In order to verify the feasibility and validity of this hybrid method, we combine the criteria importance through inter-criteria correlation (CRITIC) method with modified VIKOR for ranking the ten BEVs. The CRITIC method, proposed by Diakoulaki et al. [112], is used to calculate attributes' weights by standard deviation. As derived in Table 16, although the sorting of the BEVs based on different MCDM methods varies partly, Aion S (P3) is still the optimal choice. This means that the proposed method is effective at ranking and selecting BEV alternatives.

Finally, from the perspective of dimension, the comfort $(D)$, featuring the largest gap value $(0.467,0.276,0.311$, $0.321,0.380)$ with cars of BAOJUN E100 (P1), MG EZS (P4), Aeolus E70 (P5), BYD Yuan (P7), and EMGRAND EV (P9), should be the priority for improvement if banking managers wish to enhance service innovation. The dynamics $(A)$ dimension, constituting the largest gap value $(0.191,0.311$, $0.435)$ with cars of Aion S (P3), BESTUNE B30EV (P8), and ORA R1 (P10), should improve as a priority. In the BAIC EU Series $(P 2)$, the safety $(C)$ dimension features the largest gap with the value of 0.267 , which should be a top priority for improvement to achieve aspiration levels. In the alternative of GEOMETRY A (P6), the cost $(E)$ dimension constitutes the largest gap with the value of 0.285 . According to the same rule, the priority improvement following sustainable development context can be sequenced in the criteria for each $\mathrm{BEV}$. Given these critical empirical findings, our analysis results, as holistically formulated in Table 17, present the optimized path for different BEV models. Hence, relevant departments can not only use this method to define gaps but also enhance customers' purchase willingness in China based on the priorities of influence weights or gap values.

\section{Conclusions}

BEVs are not only the mainstream of the future automobile industry but also the top priority for implementing national energy policy and achieving sustainable development of the automobile industry. However, a large proportion of consumers still hold a wait-and-see attitude [58, 60], China's $\mathrm{BEV}$ market has always been a policy-oriented model. There is still much room for improvement in consumers' purchase willingness. This study creates a novel hybrid model combining fine-grained sentiment analysis and an MCDM model to assess BEV alternatives from the customers' point of view. In summary, the main results of this study are as follows:

(1) The comprehensive evaluation indicator system, including five dimensions (dynamics, technology, safety, comfort, and cost) and seventeen criteria, is obtained by the LDA model based on fine-grained sentiment analysis.

(2) Safety $(C)$ is the most influential dimension, followed by technology $(B)$, dynamics $(A)$, comfort $(D)$, and cost $(E)$. Safety improvements can lead to changes in other dimensions. Thus, government and providers can improve BEV attributes more flexibly and accurately based on the identification of cause-effect relationships between the dimensions and the actual situation of BEVs.

(3) The DANP analysis shows that price (E1), incentives $(E 2)$, and after-sales cost (E3) are ranked as the top criteria, and they all belong to the cost dimension. Moreover, the lowest influential weights involve suspension (D2), car seat (D3), exterior, and interior (D4), and they all belong to the comfort dimension. Government and providers can determine the order of improvement based on the weight.

(4) The modified VIKOR results indicated that the selection strategies of ten BEVs are $P 3>P 2>$ $P 4>P 8>P 6>P 9>P 5>P 7>P 10>P 1$, which presented that $P 3$ (Aion $S$ ) is the best choice. In addition, there is still room for improvement in vehicle attributes, and the indicator gaps and optimized path are different for each BEV. Taking the BEV named Aion $S$ as an example, it has the highest integrated scores, but it still falls short of aspiration levels. According to the gaps ranging from large to small, the first step of the optimized path should improve the dynamics.

(5) In this study, we find some attributes that have been neglected in previous studies, such as maximum power, max torque, and after-sales cost, affect customers' satisfaction. With the gradual maturity of BEV technology, the effects of more detailed vehicle attributes should be considered [30]. Therefore, the widespread promotion of BEVs cannot rely solely on policy incentives and the government should take active measures to promote automobile companies to achieve the urgent improvements of BEV attributes $[113,114]$.

However, there are some limitations in this study, which need to be solved in future research. First, due to the differences in consumption concepts and the influence of psychological factors, consumers can be divided into different levels for further analysis. Second, based on the 
complexity of things and the ambiguities of subjective judgments, interval numbers and fuzzy numbers can be introduced in future research on consumers' adoption of BEVs. Finally, some forecasting methods can be used to predict the motivation of consumers.

\section{Abbreviations}

\begin{tabular}{|c|c|}
\hline AHP: & Analytic hierarchy process \\
\hline ANP: & Analytic network process \\
\hline BAIC BJEV: & Beijing Automotive Industry Corporation \\
\hline & Beijing Electric Vehicle \\
\hline BEVs: & Battery electric vehicles \\
\hline BYD: & Build your dreams \\
\hline COPRAS: & Complex proportional assessment \\
\hline CRITIC: & $\begin{array}{l}\text { Criteria importance through intercriteria } \\
\text { correlation }\end{array}$ \\
\hline DANP: & DEMATEL-based analytic network process \\
\hline DC: & Direct current \\
\hline DEMATEL: & $\begin{array}{l}\text { Decision-making trial and evaluation } \\
\text { laboratory }\end{array}$ \\
\hline ELECTRE: & $\begin{array}{l}\text { ELimination and Choice Expressing the } \\
\text { REality }\end{array}$ \\
\hline EVs: & Electric vehicles \\
\hline FAW: & First automobile workshop \\
\hline GAC NE: & Guangzhou Automobile Group Co., Ltd \\
\hline GHG: & Greenhouse gas \\
\hline ICEVs: & Internal combustion engine vehicles \\
\hline INRM: & Influential network relationship map \\
\hline LCA: & Life cycle assessment \\
\hline LDA: & Latent Dirichlet Allocation \\
\hline MCDM: & Multicriteria decision-making method \\
\hline MARCOS: & $\begin{array}{l}\text { Measurement of Alternatives and Ranking } \\
\text { According to Compromise Solution }\end{array}$ \\
\hline PROMETHEE: & $\begin{array}{l}\text { Preference Ranking Organization Method } \\
\text { for Enrichment Evaluation }\end{array}$ \\
\hline R\&D: & Research and Development \\
\hline SAIC: & Shanghai Automotive Industry \\
\hline & Corporation \\
\hline SECA: & $\begin{array}{l}\text { Simultaneous Evaluation of Criteria and } \\
\text { Alternatives }\end{array}$ \\
\hline SGMW: & Shanghai General Motors Wuling \\
\hline SWARA: & $\begin{array}{l}\text { Stepwise Weight Assessment Ratio } \\
\text { Analysis }\end{array}$ \\
\hline TOPSIS: & $\begin{array}{l}\text { Technique for Order of Preference by } \\
\text { Similarity to Ideal Solution }\end{array}$ \\
\hline VIKOR: & $\begin{array}{l}\text { Vlse Kriterijuska Optimizacija I } \\
\text { Komoromisno Resenje. }\end{array}$ \\
\hline
\end{tabular}

\section{Data Availability}

The data used to support the findings of this study are available from the corresponding author upon request.

\section{Conflicts of Interest}

The authors declare that there are no conflicts of interest regarding the publication of this paper.

\section{Acknowledgments}

This study was supported by the National Natural Science Foundation of China (Grant No. 71774105), the MOE (Ministry of Education in China) Youth Foundation Project of Humanities and Social Sciences (Grant No. 18YJCZH143), the Philosophy and Social Sciences Research of Higher Learning Institutions of Shanxi (Grant No. 2019W064), and Shanxi Province Graduate Education Innovation Project in 2019 (Grant No. 2019SY402).

\section{References}

[1] T. G. Poder and J. He, "Willingness to pay for a cleaner car: the case of car pollution in Quebec and France," Energy, vol. 130, pp. 48-54, 2017.

[2] A. Ardeshiri and T. H. Rashidi, "Willingness to pay for fast charging station for electric vehicles with limited market penetration making," Energy Policy, vol. 147, Article ID 111822, 2020.

[3] International Energy Agency (IEA), Data and Statistics, International Energy Agency, Paris, France, 2020, https://www. iea.org/data-and-statistics/?country=WORLD\&fuel $=\mathrm{CO} 2 \%$ 20emissions\&indicator $=\mathrm{CO} 2 \mathrm{BySector}$.

[4] Y. W. Cheng, J. Chen, and K. Lin, "Exploring consumer attitudes and public opinions on battery electric vehicles," Journal of Renewable and Sustainable Energy, vol. 7, no. 4, Article ID 043122, 2015.

[5] J. Geng, R. Long, H. Chen, T. Yue, W. Li, and Q. Li, “'“Exploring multiple motivations on urban residents' travel mode choices: an empirical study from Jiangsu province in China," Sustainability, vol. 9, no. 1, p. 136, 2017.

[6] Z. Miao, T. Baležentis, S. Shao, and D. Chang, "Energy use, industrial soot and vehicle exhaust pollution-China's regional air pollution recognition, performance decomposition and governance," Energy Economics, vol. 83, pp. 501-514, 2019.

[7] A. Haines, A. J. McMichael, K. R. Smith et al., "Public health benefits of strategies to reduce greenhouse-gas emissions: overview and implications for policy makers," The Lancet, vol. 374, no. 9707, pp. 2104-2114, 2009.

[8] J. Du, M. Ouyang, and J. Chen, "Prospects for Chinese electric vehicle technologies in 2016-2020: ambition and rationality," Energy, vol. 120, pp. 584-596, 2017.

[9] Z. Li, A. Khajepour, and J. Song, "A comprehensive review of the key technologies for pure electric vehicles," Energy, vol. 182, pp. 824-839, 2019.

[10] L. Qian and D. Soopramanien, "Using diffusion models to forecast market size in emerging markets with applications to the Chinese car market," Journal of Business Research, vol. 67, no. 6, pp. 1226-1232, 2014.

[11] M. Song, G. Zhang, K. Fang, and J. Zhang, "Regional operational and environmental performance evaluation in China: non-radial DEA methodology under natural and managerial disposability," Natural Hazards, vol. 84, no. 1, pp. 243-265, 2016.

[12] Q. Li, R. Long, H. Chen, and J. Geng, "Low purchase willingness for battery electric vehicles: analysis and simulation based on the fault tree model," Sustainability, vol. 9, no. 5, p. 809, 2017.

[13] X. Zhang, J. Xie, R. Rao, and Y. Liang, "Policy incentives for the adoption of electric vehicles across countries," Sustainability, vol. 6, no. 11, pp. 8056-8078, 2014. 
[14] Z. Rezvani, J. Jansson, and J. Bodin, "Advances in consumer electric vehicle adoption research: a review and research agenda," Transportation Research Part D: Transport and Environment, vol. 34, pp. 122-136, 2015.

[15] X. Zhao, O. C. Doering, and W. E. Tyner, "The economic competitiveness and emissions of battery electric vehicles in China," Applied Energy, vol. 156, pp. 666-675, 2015.

[16] F. Manríquez, E. Sauma, J. Aguado, S. de la Torre, and J. Contreras, "The impact of electric vehicle charging schemes in power system expansion planning," Applied Energy, vol. 262, Article ID 114527, 2020.

[17] Y. Kwon, S. Son, and K. Jang, "User satisfaction with battery electric vehicles in South Korea," Transportation Research Part D: Transport and Environment, vol. 82, Article ID 102306, 2020.

[18] The General Office of the State Council, The New Development Plan for the NEV Industry, The General Office of the State Council, Beijing, China, 2020, http://www.gov.cn/ zhengce/content/2020-11/02/content_5556716.htm.

[19] N. Wang, L. Tang, W. Zhang, and J. Guo, "How to face the challenges caused by the abolishment of subsidies for electric vehicles in China?" Energy, vol. 166, pp. 359-372, 2019.

[20] C. Lu, H.-C. Liu, J. Tao, K. Rong, and Y.-C. Hsieh, "A key stakeholder-based financial subsidy stimulation for Chinese EV industrialization: a system dynamics simulation," Technological Forecasting and Social Change, vol. 118, pp. 1-14, 2017.

[21] X. Sun, X. Liu, Y. Wang, and F. Yuan, “The effects of public subsidies on emerging industry: an agent-based model of the electric vehicle industry," Technological Forecasting and Social Change, vol. 140, pp. 281-295, 2019.

[22] N. Wang, H. Pan, and W. Zheng, "Assessment of the incentives on electric vehicle promotion in China," Transportation Research Part A: Policy and Practice, vol. 101, pp. 177-189, 2017.

[23] A. Jenn, K. Springel, and A. R. Gopal, "Effectiveness of electric vehicle incentives in the United States," Energy Policy, vol. 119, pp. 349-356, 2018.

[24] W. Li, R. Long, and H. Chen, 'Consumers' evaluation of national new energy vehicle policy in China: an analysis based on a four paradigm model," Energy Policy, vol. 99, pp. 33-41, 2016.

[25] S. Wang, J. Fan, D. Zhao, S. Yang, and Y. Fu, "Predicting consumers' intention to adopt hybrid electric vehicles: using an extended version of the theory of planned behavior model," Transportation, vol. 43, no. 1, pp. 123-143, 2016.

[26] China Association of Automobile Manufactures (CAAM), Economic Operation of Automobile Industry, China Association of Automobile Manufactures, Beijing, China, 2020, http://www.caam.org.cn/chn/4/cate_30/list_1.html.

[27] W. Li, R. Long, H. Chen, and J. Geng, "A review of factors influencing consumer intentions to adopt battery electric vehicles," Renewable and Sustainable Energy Reviews, vol. 78, pp. 318-328, 2017.

[28] H.-C. Liu, X.-Y. You, Y.-X. Xue, and X. Luan, "Exploring critical factors influencing the diffusion of electric vehicles in China: a multi-stakeholder perspective," Research in Transportation Economics, vol. 66, pp. 46-58, 2017.

[29] G. Cecere, N. Corrocher, and M. Guerzoni, "Price or performance? A probabilistic choice analysis of the intention to buy electric vehicles in European countries," Energy Policy, vol. 118, pp. 19-32, 2018.
[30] F. Liao, E. Molin, and B. van Wee, "Consumer preferences for electric vehicles: a literature review," Transport Reviews, vol. 37, no. 3, pp. 252-275, 2017.

[31] F. Nazari, E. Rahimi, and A. K. Mohammadian, "Simultaneous estimation of battery electric vehicle adoption with endogenous willingness to pay," eTransportation, vol. 1, Article ID 100008, 2019.

[32] K. Petrauskienè, M. Skvarnavičiūtè, and J. Dvarionienè, "Comparative environmental life cycle assessment of electric and conventional vehicles in Lithuania," Journal of Cleaner Production, vol. 246, Article ID 119042, 2020.

[33] J. Shin, W.-S. Hwang, and H. Choi, "Can hydrogen fuel vehicles be a sustainable alternative on vehicle market?: comparison of electric and hydrogen fuel cell vehicles," Technological Forecasting and Social Change, vol. 143, pp. 239-248, 2019.

[34] F. Ecer, "A consolidated MCDM framework for performance assessment of battery electric vehicles based on ranking strategies," Renewable and Sustainable Energy Reviews, vol. 143, Article ID 110916, 2021.

[35] H. C. Sonar and S. D. Kulkarni, "An integrated AHPMABAC approach for electric vehicle selection," "Research in Transportation Business \& Management, vol. 260, Article ID 100665, 2021.

[36] J. Bas, C. Cirillo, and E. Cherchi, "Classification of potential electric vehicle purchasers: a machine learning approach," Technological Forecasting and Social Change, vol. 168, Article ID 120759, 2021.

[37] D. De Clercq, N. F. Diop, D. Jain, B. Tan, and Z. Wen, "Multilabel classification and interactive NLP-based visualization of electric vehicle patent data," World Patent Information, vol. 58, Article ID 101903, 2019.

[38] T. Yang, C. Xing, and X. Li, "Evaluation and analysis of newenergy vehicle industry policies in the context of technical innovation in China," Journal of Cleaner Production, vol. 281, Article ID 125126, 2021.

[39] M. Naumanen, T. Uusitalo, E. Huttunen-Saarivirta, and R. van der Have, "“Development strategies for heavy duty electric battery vehicles: comparison between China, EU, Japan and USA," Resources, Conservation and Recycling, vol. 151, Article ID 104413, 2019.

[40] D. Aguilar-Dominguez, J. Ejeh, A. D. F. Dunbar, and S. F. Brown, "Machine learning approach for electric vehicle availability forecast to provide vehicle-to-home services," Energy Reports, vol. 7, pp. 71-80, 2021.

[41] R. Basso, B. Kulcsár, and I. Sanchez-Diaz, "Electric vehicle routing problem with machine learning for energy prediction," Transportation Research Part B: Methodological, vol. 145, pp. 24-55, 2021.

[42] S.-C. Ma, Y. Fan, J.-F. Guo, J.-H. Xu, and J. Zhu, "Analysing online behaviour to determine Chinese consumers' preferences for electric vehicles," Journal of Cleaner Production, vol. 229, pp. 244-255, 2019.

[43] A. Alsaeedi and M. Z. Khan, "A study on sentiment analysis techniques of twitter data," International Journal of Advanced Computer Science and Applications, vol. 10, no. 2, pp. 361-374, 2019.

[44] R. Jena, "An empirical case study on Indian consumers' sentiment towards electric vehicles: a big data analytics approach," Industrial Marketing Management, vol. 90, pp. 605-616, 2020.

[45] W.-Y. Chiu, G.-H. Tzeng, and H.-L. Li, "A new hybrid MCDM model combining DANP with VIKOR to improve 
e-store business," Knowledge-Based Systems, vol. 37, pp. 48-61, 2013.

[46] M. H. Aghdaie, S. H. Zolfani, and E. K. Zavadskas, "Decision making in machine tool selection: an integrated approach with SWARA and COPRAS-G methods," Energy Economics, vol. 24, no. 1, pp. 5-17, 2013.

[47] C. Li, M. Negnevitsky, X. Wang, W. L. Yue, and X. Zou, "Multi-criteria analysis of policies for implementing clean energy vehicles in China," Energy Policy, vol. 129, pp. 826840, 2019.

[48] N. C. Onat, S. Gumus, M. Kucukvar, and O. Tatari, "Application of the TOPSIS and intuitionistic fuzzy set approaches for ranking the life cycle sustainability performance of alternative vehicle technologies," Sustainable Production and Consumption, vol. 6, pp. 12-25, 2016.

[49] S. Çali and S. Y. Balaman, "A novel outranking based multi criteria group decision making methodology integrating ELECTRE and VIKOR under intuitionistic fuzzy environment," Expert Systems with Applications, vol. 119, pp. 36-50, 2019.

[50] E. Strantzali, K. Aravossis, and G. A. Livanos, "Evaluation of future sustainable electricity generation alternatives: the case of a Greek island," Renewable and Sustainable Energy Reviews, vol. 76, pp. 775-787, 2017.

[51] M. C. Das, A. Pandey, A. K. Mahato, and R. K. Singh, "Comparative performance of electric vehicles using evaluation of mixed data," Opsearch, vol. 56, no. 3, pp. 1067-1090, 2019.

[52] G. H. Tzeng, C. W. Lin, and S. Opricovic, "Multi-criteria analysis of alternative-fuel buses for public transportation," Energy Policy, vol. 33, no. 11, pp. 1373-1383, 2005.

[53] H. Liang, J. Ren, R. Lin, and Y. Liu, "Alternative-fuel based vehicles for sustainable transportation: a fuzzy group decision supporting framework for sustainability prioritization," Technological Forecasting and Social Change, vol. 140, pp. 33-43, 2019.

[54] S. M. Skippon, N. Kinnear, L. Lloyd, and J. Stannard, "How experience of use influences mass-market drivers' willingness to consider a battery electric vehicle: a randomised controlled trial," Transportation Research Part A: Policy and Practice, vol. 92, pp. 26-42, 2016.

[55] R. Liu, Z. Ding, X. Jiang, J. Sun, Y. Jiang, and W. Qiang, "How does experience impact the adoption willingness of battery electric vehicles? The role of psychological factors," Environmental Science and Pollution Research, vol. 27, no. 20, pp. 25230-25247, 2020.

[56] J. H. Kim, G. Lee, J. Y. Park, J. Hong, and J. Park, "Consumer intentions to purchase battery electric vehicles in Korea," Energy Policy, vol. 132, pp. 736-743, 2019.

[57] W. Li, R. Long, H. Chen, and J. Geng, "Household factors and adopting intention of battery electric vehicles: a multigroup structural equation model analysis among consumers in Jiangsu Province, China," Natural Hazards, vol. 87, no. 2, pp. 945-960, 2017.

[58] Z.-Y. She, Q. Qing Sun, J.-J. Ma, and B.-C. Xie, "What are the barriers to widespread adoption of battery electric vehicles? A survey of public perception in Tianjin, China," Transport Policy, vol. 56, pp. 29-40, 2017.

[59] X. Dong, B. Zhang, B. Wang, and Z. Wang, "Urban households' purchase intentions for pure electric vehicles under subsidy contexts in China: do cost factors matter?" Transportation Research Part A: Policy and Practice, vol. 135, pp. 183-197, 2020.
[60] L. Li, Z. Wang, L. Chen, and Z. Wang, "Consumer preferences for battery electric vehicles: a choice experimental survey in China," Transportation Research Part D: Transport and Environment, vol. 78, Article ID 102185, 2020.

[61] M. Kukova, C. Diels, P. Jordan, M. Franco-Jorge, J. Anderson, and H. Kharouf, "Do we really know which vehicle attributes are important for customers," in Proceedings of the 10th International Conference on Design \& Emotion, pp. 27-30, Amsterdam, Netherlands, September 2016.

[62] S. Almeida Neves, A. Cardoso Marques, and J. Alberto Fuinhas, "Technological progress and other factors behind the adoption of electric vehicles: empirical evidence for EU countries," Research in Transportation Economics, vol. 74, pp. 28-39, 2019.

[63] C. F. Chen, G. Z. de Rubens, L. Noel, J. Kester, and B. K. Sovacool, "Assessing the socio-demographic, technical, economic and behavioral factors of Nordic electric vehicle adoption and the influence of vehicle-to-grid preferences," Renewable and Sustainable Energy Reviews, vol. 121, Article ID 109692, 2020.

[64] T. L. Saaty, Decision Making with Dependence and Feedback: The Analytic Network Process, RWS Publications, Pittsburgh, PA, USA, 1996.

[65] D. M. Blei, "Probabilistic topic models," Communications of the ACM, vol. 55, no. 4, pp. 77-84, 2012.

[66] D. Blei, M. Jordan, and A. Y. Ng, "Latent dirichlet allocation," Journal of machine Learning research, vol. 3, pp. 8993-1022, 2003.

[67] İ. Gölcük and A. Baykasoğlu, "An analysis of DEMATEL approaches for criteria interaction handling within ANP," "Expert Systems with Applications, vol. 46, pp. 346-366, 2016.

[68] A. Gabus and E. Fontela, World Problems, an Invitation to Further Thought within the Framework of DEMATEL, Battelle Geneva Research Center, Geneva, Switzerland, 1972.

[69] K.-Y. Shen, S.-K. Hu, and G.-H. Tzeng, "Financial modeling and improvement planning for the life insurance industry by using a rough knowledge based hybrid MCDM model," Information Sciences, vol. 375, pp. 296-313, 2017.

[70] S. K. Liao, H. Y. Hsu, and K. L. Chang, "OTAs selection for hot spring hotels by a hybrid MCDM model," Mathematical Problems in Engineering, vol. 2019, Article ID 4251362, 9 pages, 2019.

[71] Y. Su, D. Liang, and W. Guo, "Application of multiattribute decision-making for evaluating regional innovation capacity," Mathematical Problems in Engineering, vol. 2020, Article ID 2851840, 20 pages, 2020.

[72] W. Song, Y. Zhu, and Q. Zhao, “Analyzing barriers for adopting sustainable online consumption: a rough hierarchical DEMATEL method," Computers \& Industrial Engineering, vol. 140, Article ID 106279, 2020.

[73] Q. Zhao, P. H. Tsai, and J. L. Wang, “"Improving financial service innovation strategies for enhancing China's banking industry competitive advantage during the fintech revolution: a hybrid MCDM model," Sustainability, vol. 11, no. 5, p. 1419, 2019.

[74] S.-B. Tsai, "Using the DEMATEL model to explore the job satisfaction of research and development professionals in China's photovoltaic cell industry," Renewable and Sustainable Energy Reviews, vol. 81, pp. 62-68, 2018.

[75] J. J. H. Liou, G.-H. Tzeng, and H.-C. Chang, "Airline safety measurement using a hybrid model," Journal of Air Transport Management, vol. 13, no. 4, pp. 243-249, 2007. 
[76] W.-S. Lee, G.-H. Tzeng, J.-L. Guan, K.-T. Chien, and J.-M. Huang, "Combined MCDM techniques for exploring stock selection based on Gordon model," Expert Systems with Applications, vol. 36, no. 3, pp. 6421-6430, 2009.

[77] R. Wang, X. Li, C. Xu, and F. Li, "Study on location decision framework of electric vehicle battery swapping station: using a hybrid MCDM method," Sustainable Cities and Society, vol. 61, Article ID 102149, 2020.

[78] Y.-P. Ou Yang, H.-M. Shieh, and G.-H. Tzeng, "A VIKOR technique based on DEMATEL and ANP for information security risk control assessment," Information Sciences, vol. 232, pp. 482-500, 2013.

[79] R. Liu, H. Sun, L. Zhang et al., "Low-carbon energy planning: a hybrid MCDM method combining DANP and VIKOR approach," Energies, vol. 11, no. 12, p. 3401, 2018.

[80] H.-C. Liu, J.-X. You, L. Zhen, and X.-J. Fan, "A novel hybrid multiple criteria decision making model for material selection with target-based criteria," Materials \& Design, vol. 60, pp. 380-390, 2014.

[81] G. Büyüközkan and S. Güleryüz, "An integrated DEMATELANP approach for renewable energy resources selection in Turkey," International Journal of Production Economics, vol. 182, pp. 435-448, 2016.

[82] S. Opricovic, Multicriteria Optimization of Civil Engineering Systems, Vol. 2, Faculty of Civil Engineering, Belgrade, Serbia, 1998.

[83] P. L. Yu, "A class of solutions for group decision problems," Management Science, vol. 19, no. 8, pp. 936-946, 1973.

[84] S. Opricovic and G.-H. Tzeng, "Compromise solution by MCDM methods: a comparative analysis of VIKOR and TOPSIS," European Journal of Operational Research, vol. 156, no. 2, pp. 445-455, 2004.

[85] S. Opricovic and G.-H. Tzeng, "Extended VIKOR method in comparison with outranking methods," European Journal of Operational Research, vol. 178, no. 2, pp. 514-529, 2007.

[86] M. Achtnicht, G. Bühler, and C. Hermeling, "The impact of fuel availability on demand for alternative-fuel vehicles," Transportation Research Part D: Transport and Environment, vol. 17, no. 3, pp. 262-269, 2012.

[87] Y. Zhang, Z. Qian, F. Sprei, and B. Li, "The impact of car specifications, prices and incentives for battery electric vehicles in Norway: choices of heterogeneous consumers," Transportation Research Part C: Emerging Technologies, vol. 69, pp. 386-401, 2016.

[88] J. P. Helveston, Y. Liu, E. M. Feit, E. Fuchs, E. Klampfl, and J. J. Michalek, "Will subsidies drive electric vehicle adoption? Measuring consumer preferences in the U.S. and China," Transportation Research Part A: Policy and Practice, vol. 73, pp. 96-112, 2015.

[89] E. Valeri and R. Danielis, "Simulating the market penetration of cars with alternative fuelpowertrain technologies in Italy," Transport Policy, vol. 37, pp. 44-56, 2015.

[90] L. Noel, A. Papu Carrone, A. F. Jensen, G. Zarazua de Rubens, J. Kester, and B. K. Sovacool, "Willingness to pay for electric vehicles and vehicle-to-grid applications: a Nordic choice experiment," Energy Economics, vol. 78, pp. 525-534, 2019.

[91] B. Junquera, B. Moreno, and R. Álvarez, "Analyzing consumer attitudes towards electric vehicle purchasing intentions in Spain: technological limitations and vehicle confidence," "Technological Forecasting and Social Change, vol. 109, pp. 6-14, 2016.

[92] S.-C. Ma, J.-H. Xu, and Y. Fan, "Willingness to pay and preferences for alternative incentives to $\mathrm{EV}$ purchase subsidies: an empirical study in China," Energy Economics, vol. 81, pp. 197-215, 2019.

[93] A. F. Jensen, E. Cherchi, and J. de Dios Ortúzar, "A long panel survey to elicit variation in preferences and attitudes in the choice of electric vehicles," Transportation, vol. 41, no. 5, pp. 973-993, 2014.

[94] M. K. Hidrue, G. R. Parsons, W. Kempton, and M. P. Gardner, "Willingness to pay for electric vehicles and their attributes," Resource and Energy Economics, vol. 33, no. 3, pp. 686-705, 2011.

[95] P. Ayoung-Chee, C. D. Mack, R. Kaufman, and E. Bulger, "Predicting severe injury using vehicle telemetry data," Journal of trauma and acute care surgery, vol. 74, no. 1, pp. 190-195, 2013.

[96] F. Bühler, P. Cocron, I. Neumann, T. Franke, and J. F. Krems, "Is EV experience related to EV acceptance? Results from a German field study," Transportation Research Part F: Traffic Psychology and Behaviour, vol. 25, pp. 34-49, 2014.

[97] P. Cocron, F. Bühler, T. Franke, I. Neumann, B. Dielmann, and J. F. Krems, "Energy recapture through deceleration regenerative braking in electric vehicles from a user perspective," Ergonomics, vol. 56, no. 8, pp. 1203-1215, 2013.

[98] F. Schmalfuß, K. Mühl, and J. F. Krems, "Direct experience with battery electric vehicles (BEVs) matters when evaluating vehicle attributes, attitude and purchase intention," Transportation Research Part F: Traffic Psychology and Behaviour, vol. 46, pp. 47-69, 2017.

[99] G. Long, F. Ding, N. Zhang, J. Zhang, and A. Qin, "Regenerative active suspension system with residual energy for in-wheel motor driven electric vehicle," Applied Energy, vol. 260, Article ID 114180, 2020.

[100] L. Zhang and Q. Qin, “China's new energy vehicle policies: evolution, comparison and recommendation," Transportation Research Part A: Policy and Practice, vol. 110, pp. 57-72, 2018.

[101] M. M. Lopes, F. Moura, and L. M. Martinez, “A rule-based approach for determining the plausible universe of electric vehicle buyers in the Lisbon Metropolitan Area," Transportation Research Part A: Policy and Practice, vol. 59, pp. 22-36, 2014.

[102] P. Weldon, P. Morrissey, and M. O’Mahony, "Long-term cost of ownership comparative analysis between electric vehicles and internal combustion engine vehicles," Sustainable Cities and Society, vol. 39, pp. 578-591, 2018.

[103] N. Wang, L. Tang, and H. Pan, "Effectiveness of policy incentives on electric vehicle acceptance in China: a discrete choice analysis," Transportation Research Part A: Policy and Practice, vol. 105, pp. 210-218, 2017.

[104] W. Li, R. Long, H. Chen, T. Yang, J. Geng, and M. Yang, "Effects of personal carbon trading on the decision to adopt battery electric vehicles: analysis based on a choice experiment in Jiangsu, China," Applied Energy, vol. 209, pp. 478488, 2018.

[105] X. Zhang, Y. Liang, E. Yu, R. Rao, and J. Xie, "Review of electric vehicle policies in China: content summary and effect analysis," Renewable and Sustainable Energy Reviews, vol. 70, pp. 698-714, 2017.

[106] M.-K. Kim, J. Oh, J.-H. Park, and C. Joo, "Perceived value and adoption intention for electric vehicles in Korea: moderating effects of environmental traits and government supports," Energy, vol. 159, pp. 799-809, 2018.

[107] C. Y. Huang and I. Tung, "Strategies for heterogeneous R\&D alliances of in vitro diagnostics firms in rapidly catching-up 
economies," International Journal of Environmental Research and Public Health, vol. 17, no. 10, 2020.

[108] T. Lieven, S. Mühlmeier, S. Henkel, and J. F. Waller, "Who will buy electric cars? An empirical study in Germany," Transportation Research Part D: Transport and Environment, vol. 16, no. 3, pp. 236-243, 2011.

[109] S. Skippon and M. Garwood, "Responses to battery electric vehicles: UK consumer attitudes and attributions of symbolic meaning following direct experience to reduce psychological distance," Transportation Research Part D: Transport and Environment, vol. 16, no. 7, pp. 525-531, 2011.

[110] Y. Liu, Y. Yang, Y. Liu, and G. H. Tzeng, "Improving sustainable mobile health care promotion: a novel hybrid MCDM method," Sustainability, vol. 11, no. 3, 2019.

[111] F. Del Pero, M. Delogu, and M. Pierini, "The effect of lightweighting in automotive LCA perspective: estimation of mass-induced fuel consumption reduction for gasoline turbocharged vehicles," Journal of Cleaner Production, vol. 154, pp. 566-577, 2017.

[112] D. Diakoulaki, G. Mavrotas, and L. Papayannakis, "Determining objective weights in multiple criteria problems: the critic method," Computers \& Operations Research, vol. 22, no. 7, pp. 763-770, 1995.

[113] Q. Qiao, F. Zhao, H. Hao, S. Jiang, and Z. Liu, "Cradle-togate greenhouse gas emissions of battery electric and internal combustion engine vehicles in China," Applied Energy, vol. 204, 2017.

[114] I. A. Nienhueser and Y. Qiu, "Economic and environmental impacts of providing renewable energy for electric vehicle charging-a choice experiment study," Applied Energy, vol. 180, pp. 256-268, 2016. 